\title{
Beiträge zur Geschichte der deutschen Sprache und Literatur
}

Herausgegeben von Karin Donhauser, Klaus Grubmüller und Jan-Dirk Müller unter Mitwirkung von Hans Fromm und Rudolf Große

Band 129 (2007)

Niemeyer

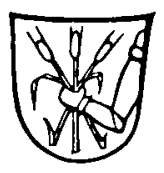




\title{
HEILSWUNDER UND FAULER ZAUBER
}

\author{
Repräsentationen religiöser Praxis \\ in frühmodernen Schwankerzählungen
}

\section{Schwank, Pluralisierung und religiöse Praxis}

Messfeier und Predigt, Heiligenverehrung und Almosengabe: Die Handlungszusammenhänge religiöser Praktiken sind in der Kleinepik von Mittelalter und Früher Neuzeit nahezu ubiquitär. Zu deren Erzählduktus gehören ironische oder aggressive, obszöne, polemische oder satirische Distanzierungen solcher Praktiken und ihrer Akteure. Verschlagene Mönche und naive Nonnen, betrügerische Priester oder einfältige Fromme beiderlei Geschlechts bevölkern die epischen Welten von Anekdote, Exempel, Fazetie, Witz, Fabel, Schwank oder Novelle. Der Wahrheitsanspruch der Predigt kann dort in der Allgegenwart der Lüge zerrieben, das Mirakel als fauler Zauber erwiesen, die Messe obszön invertiert, der heilige Ernst komisch vernichtet werden. Und unter welchen anthropologischen ${ }^{1}$ oder sozialpsychologischen $^{2}$ Deutungsvorgaben man sich ihm auch nähern mag, stets

1 Etwa ,Lachkultur: Michail Bachtin, Rabelais und seine Welt. Volkskultur als Gegenkultur, Frankfurt/M. 1987, S. 52-56; Norbert Schindler, Karneval, Kirche und verkehrte. Welt. Zur Funktion der Lachkultur im 16. Jahrhundert, in: Jahrbuch für Volkskunde: N. F. 7 (1984), S. 9-57; Wemer Röcke, Aggression und Disziplin. Gebrauchsformen des Schwanks in deutschen Eryählsammlungen des 16. Jahrhunderts, in: Walter Haug, Burghart Wachinger (IIgg.), Kleinere Erzählformen des 15. und 16. Jahrhunderts, 'Tübingen 1993 (Fortuna vitrea 8), s. 106 129, bes. S. 114 ff.; Ians-.Jürgen Bachorski [u.a.], Performativität und Lachkultur in Mittelalter und früher Neuzeit, in: Paragrana 10 (2001), \$. 157-190; zuletzt Werner Röcke, Hans Rudolf Velten (Hgg.), Iachgemeinschaften. Kulturelle Inszenierungen und soziale Wirkungen von Gelachter im Mittelalter und in der Frïhen Neuzeit, Berlin, New York 2005 (Trends in Medieval Philology 4). - Heralich danke ich Marion Oswald (Dresden) und Michael Waltenberger (München) für Gespräche und IIlfestellungen, die diesem Aufsatz sehr zugute gekommen sind. Zunächst sollte er in englischer Fassung erscheinen, doch hat sich die: Inucklegung des Bandes aus äuşeren (iründen so verzögert, dass er unglïcklicherweise erst nach dieser deutschsprachigen Version publiziert werden wird: Andreas Itöfele [u.a.] (Hgg.), Representing Religious Pluralization in Early Morlem Europe, Münster 2008 .

2 Zum Beispiel , Kompensation/Ventilfunktions: Hauke Stroszeck, P'ointe und poetische Dominante. Deutsche Kurzprosa im 16. Jahrhundert, Frankfurt/M. 1970 (Germanistik 1), S. 120; Wilfried Barmer, Legitimierung des Anstößigen: Ïber Poggios und Bebels Fazetien, in: Hansgerd I)elbrück (IIg.), Sinnlichkeit in Bild und Klang. Fs. für Paul Hoffmann zum 70. Geburtstag, Stuttgart 1987 (Stut.tgarter Arbeiten zur Germanistik 189), S. 101-137, hier S. 110 f.; Walter Haug, Enlwurf zu einer Theorice der mittelalterlichen Kurzerzahlung |19933], in: ders., Brechun- 
wird man doch sagen können, dass solches Erzählen eine Form der Spannungsinstitutionalisierung sei: ${ }^{3}$ Aus der Entgegensetzung von Gültigem und Nichtigem bezieht es seine Dynamik und entbindet es gegebenenfalls seine Komik. ${ }^{4}$ Keineswegs verwunderlich also, dass immer wieder der religiöse Tabubruch und die Profanierung des Sakralen das Material für solche narrativen Konstitutionsprozesse bilden: Weil es bei ihm stets um die überhaupt fundierenden epistemischen und institutionellen Strukturen vormoderner Kulturen geht, bietet das Sakrale die bei weitem größten Potentiale für den Aufbau solcher narrativen Spannungskonstellationen.

Über diese poesiologische Dimension hinaus kann in solchem Erzählen freilich auch ein schaudern machender kalter Blick auf die Welt sich manifestieren, der nichts sieht als den schwarzen Abgrund der restlosen Negation all dessen, was das normativ Richtige, das moralisch Gute wäre; der lateinische >Ysengrimus oder mittelhochdeutsche Schwankmären wie das

gen auf dem Weg zur Individualität. Kleine Schriften zur Literatur des Mittelalters, Tübingen 1995, S. 427-454, hier S. 452-454. Vgl. Gerd Dicke, Fazetieren. Ein Konversationstyp der italienischen Renaissance und seine deutsche Rezeplion im 15. und 16. Jahrhundert, in: Eckart Conrad Lutz [u.a.] (Hgg.), Literatur und Wandmalerei II. Konventionalität und Konversation. Burgdorfer Colloquium 2001, Tübingen 2005, S. 155-188, hier S. $157 \mathrm{f}$, 163, 174f., $183 \mathrm{ff}$.

$\therefore$ Ich adaptiere also versuchsweise einen Begriff von Arnold Gehlen (Umensch und Spätkultur. Philosophische Ergebnisse und Aussagen, 5. Aufl., Wiesbaden 1986, S. 78-84; vgl. Karl-Siegbert Rehberg, Weltrepräsentanz und Verkörperung. Institutionelle Analyse und Symboltheorien - Eine Einführung in systematischer Absicht, in: Gert Melville (Hg.), Institutionalität und Symbolisierung. Verstetigungen kullureller Ordnungsmuster in Vergangenheit und Gegenwart, Köln [u.a.] 2001, S. 3-49, hier S. 13 ff.) für die historische Erzählforschung: Wie Lotmans Sujet-Begriff (vgl. Jurij M. Lotman, Die Struktur literarischer Texte, übers. v. Rolf-I)ietrich Keil, München 1972, S. 329-341; ders., Die Entstehung des Sujots - typologisch gesehen, in: ders., Kunst als Sprache. Untersuchungen zum Zeichencharakter von Literatur und Kunst, hg. v. Klaus Städke, Leipzig 1981, S. 175-204) setzt das Konzept institutionalisierter Spannungen eine Differenz (Grenze, Ereignis) innerhalb eines semantischen Feldes voraus, anders als jener könnte es aber bewusst halten, dass allein der >Held die Grenze überschreitet (und damit auslöscht), die Erzählung aber, indem sie davon crzählt, diese Grenze gerade als solche, d.h. die epische Welt als eine Zwei-Seiten-Form stabilisieren kann.

1 Vgl. Joachim Ritter, Ijber das Lachen [1940], in: ders., Subjektivität. 6 Aufsätze, Frankfurt/M. 1974 (Bibliothek Suhrkamp 379), S. 62-92; Wolfgang Preisendanz, Rainer Warning (Hgg.), I)as Komische, München 1976 (Poetik und Hermeneutik 7). - Eine: Erweitcrung der solche Komik generierenden "Logik der Inkongruenz um "die Formen [ihrer] Inszenierung, [ihrer] Institutionalisierung und aggressiven Körperlichkeit a mach gellend Wener Rörke, Lizenzen des Witzes. Institutionen und Funktionsweisen der Fazetie im Spätmittelalter, in: ders., Ilelga Neumann (IIgg.), Komische Gegenwelten. Lachen und Literatur in Mittelaller und Friber Newzeit, Paderborn [u.a.] 1999, S. 79-101, Zilat. S. 85; vgl. auch IJans-Jiirgen Bachorski, l'oggios Facelien und das P'roblem der Performativilät des toten Witzes, in: Zf(i 11 (2001), S.:318-3355, und zuletzt Röcke/Velten [Anm. 1]. 
im 15. Jahrhundert entstandene 'Nonnenturnier könnten etwa in derartigem Zusammenhang diskutiert werden. ${ }^{5}$ Selbst in solchen Texten wird indessen die Entgegensetzung von Gültigem und Nichtigem als solche nicht außer Kraft gesetzt. Sie verzichten wohl auf die explizite Affirmation eines totalisierenden Letztbegründungsrahmens. Ungeachtet dessen setzen sie in ihrer Poetik der radikalen Negativierung einen solchen Rahmen jedoch als Bedingung ihrer Möglichkeit, mindestens der Möglichkeit ihres kommunikativen Funktionierens voraus. Auch die Abgründe ihrer epischen Welten funktionieren noch im Schema der (nichtigen) Abweichung von der (gültigen) Norm, von Negierung und Positivität. Es handelt sich daher nicht um Pluralisierungsphänomene in jenem distinkten Sinne, wie ihn das Forschungsprogramm des Sonderforschungsbereichs 573 »Pluralisierungen und Autorität in der Frühen Neuzeit « expliziert ${ }^{6}$ und wie ich ihn hier - nicht ohne Spezifikationen im Hinblick auf das Erkenntnisziel meines Aufsatzes - zu Grunde lege.

Demnach bezöge sich >Pluralisierung ‘ nicht auf frühneuzeitliche Vervielfältigungen gesellschaftlicher Ausdifferenzierungsmuster schon als solche, nicht auf Komplexisierungen voneinander abgesetzter Wissensfelder uberhaupt, auf fortschreitende Entmonopolisierungen von Wahrheitsansprüchen oder auf das Anwachsen soziokommunikativer Legitimierungsalternativen. Geschichtlichen Wandel solcher Art gibt es in der einen oder anderen Form ja immer. Reservierte man die Kategorie der >Pluralisierung für solcherlei, sie würde eine gewissermaßen bloß quantitative Seite der Frühen Neuzeit fassen: ,größere Vielfalt, 'schnellerer Wandel als sonst. Frühneuzeitliche Epochenspezifik wäre so vermutlich nicht recht auf den Begriff zu bringen. Entscheidend wären nicht schon Diversifikationen, Alternativenbildungen, Komplexisierungen selbst, sondem vielmehr ihre Verarbeitung im semantischen Haushalt der Gesellschaft, in den kollektiven Ordnungen des Wissens - und zwar: ihre Verarbeitung eben als Steigerung von Unübersichtlichkeit und Erschwerung von Orientiertheit. Entscheidend wäre für >Pluralisierung - so würde ich sagen -, dass solche

-Vgl. in diesem Zusammenhang insbesondere Werner Röcke, IDje Freucle am Bosen. Studien zu einer Poetik des deutschen Schwankromans im Spätmittelalter, München 1987 (Forschungen zur (ieschichte der äteren deutschen Literatur 6); Klaus (xrubmüller, Das Groteske im Märe als Element seiner Geschichte. Skizzen zu einer historischen (iattungspoetik, in: Haug/Wachinger [Anm. 1], \$. :37-54; I laug [Anm. 2).

"Vgl. den Antrag auf Finanzierung eines Sonderforschungsbereichs "Pluralisierung und Autorität in der Frühen Neuzeit (15, - 17. Jahrhundert) «, Ludwig-Maximilians-I niversität München 2000, S. 9-14, und bes. den Antrag auf Finanzicrung des Sonderforschungsbereichs "Pluralisierung und Autoritat in der Frihent Neuzeit (15.-17. Jahrhundert) «, Ludwig-Maximilians-t Jniversität Minchen 200:3, S. 6 . 9, 1:3 15, projektsperifisch chol., S. $285 \mathrm{f}$. 
Alternativen zum Gültigen, welche bislang ohne weiteres negierbar gewesen waren und etwa als Nichtiges klassifiziert werden konnten, dass sie diese Negierbarkeit verlieren.

>Pluralisierung < würde so zu einer Kategorie für die Analyse kollektiven Wissens und kultureller Semantiken. Der Begriff zielte auf geschichtliche >Pluralisierungserfahrungen< und deren diskursive Verarbeitung. Diese müssen keineswegs in einer expliziten Semantik der >Pluralisierung، manifest werden, doch zeigen sie sich dort, wo Unvereinbarkeiten von Sachverhalten, Konkurrenzen von Legitimitätsansprüchen, Gegenstrebigkeiten von Subsumptionsverhältnissen (Regel - Fall, Oberbegriff - Unterbegriff) usw. nicht mehr in Schematismen wie >Norm und Abweichung<, >Gültiges und Nichtiges plausibel zu deuten sind. Von frühneuzeitlicher Pluralisierung in distinktem Sinne mag insofern eben dann die Rede sein, wenn angesichts von Vielzahl und Vielfalt, von Disparitäten und Kontingenzen der Rekurs auf - wie ich im Anschluss an Reinhart Koselleck sagen möchte - asymmetrische Gegenbegriffe ${ }^{7}$ seine Funktion epistemischer Stabilisierung einbüßt. Solche Fälle liegen zum Beispiel vor, wenn nicht (mehr) ethisch zwischen ,gut und >böse oder epistemisch zwischen

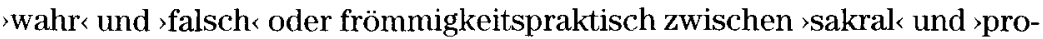
fan< verlässlich unterschieden werden kann; wenn - um im Bereich religiöser Überzeugungen und Praktiken zu bleiben - die Deutungsleistung von binären Termen wie >Christ/Heide $<$ oder $>$ Heiliger/Ketzer $<$ oder $>$ Christ $/$ Papist $`$ oder >Frömmigkeit/Blasphemie gerade nicht trägt; wenn unabgestimmte Kontiguitäten des Einen und des Anderen an die Stelle der Negierbarkeit des Anderen durch das Eine treten. In solchen Lagen verlieren asymmetrische, also werthierarchisch besetzte Gegenbegriffe (wie >Christ/ Heides) und die ihnen zu Grunde liegenden Leitdifferenzen ihre kulturell selbstverständliche Deutungs- und Orientierungsleistung, während zugleich symmetrische, etwa in heterarchischen Funktionssystemen operierende Gegenbegriffe (das vermutlich wichtigste Beispiel wäre sdie eine Kultur/die andere Kultur $\left.{ }^{8}\right)$ nicht zur Verfügung stehen.

' Reinhart Koselleck, Zur historisch-politischen Semantik asymmetrischer Gegenbegriffe, in: Harald Weinrich (Hg.), Positionen der Negativität, München 1975 (Poetik und Hermeneutik 6), S. 65-104. Hier wird das Konzept vor allem an den Begriffspaaren ,Hellene - Barbars, >Christ - Heides und >Mensch - Unmensch erprobt.

"Vgl. hicrzu Dirk Baecker, Wozu Kultur?, Berlin 2000. - Jenseits der Interessen der gegenwärtigen Studie kann vielleicht hinzugefügt werden: jener langwierige historische Vorgang einer gewissen Symmetrisierung von Differenz, in welchem von dem Modell thellene - Barbar ‘ auf das sKultur - Kultur-Paradigma der globalisierten Welt (ebd., S. 11 ff.) umgestellt wird; er gehört freilich in den Zusammenhang der Kränkungsgeschichte abendländischer Identität: Dem Herausfallen aus der Mitte des Kosmos (Kopernikus) sowie den Verlusten von Herausgehobenheit gegenüber dor Natur، (I)arwin) und von Selbstmächtigkeit (Freud) 
Ein solcher begrifflicher Ausgangspunkt, wie ich ihn hier skizziere, bestimmt >Pluralisierung< vergleichsweise eng als eine Prozesskategorie der - wie man auch sagen könnte - (wissenschaftlichen) Beobachtung von kulturellen Selbstbeobachtungen, und zwar näherhin solcher kulturellen Selbstbeobachtungen, in denen so fundamentale wie etablierte Kategorisierungen der Weltauslegung versagen und die sich daher als schwer oder nicht zu bewältigende Kontingenzerfahrung darstellen. Dieser terminologische Ansatz ist selbstverständlich nicht ohne Risiken. ${ }^{9}$ Immerhin führt er jedoch auf die Pointe, dass >Pluralisierung , auch religiöse >Pluralisierung nicht ohne weiteres mit frühmodemen Konfessionsbildungsvorgängen ${ }^{10}$ zusammenkommt; und an dieser Pointe besteht - von den im Folgenden zu beschreibenden Texten her gesehen - zum Mindesten ein heuristisches Interesse.

Wohl vollzieht sich Konfessionsbildung in langfristigen und widerspruchsreichen Prozessen als Vervielfältigung dogmatischer Systeme, sozialer Bindungsformen, liturgischer Ordnungen und frömmigkeitspraktischer Orientierungen, als gesteigerte Alternativität von religiösen Verbindlichkeitszusammenhängen, Traditionen und Letztgeltungsinstanzen. Doch werden dabei Wahrheitsansprüche nicht einfach demonopolisiert, sondern auf neue Instanzen und Geltungsbereiche verschoben, vielmehr also bereichsspezifisch modifiziert. Funktionale Differenzierung kann in solchen Zusammenhängen dann eine Lösung darstellen für das Problem, wie derartige Bereiche gleichwohl - unter Invisibilisierung ihrer Antagonismen ${ }^{11}$ - zu koordinieren wären. Und sie kann sich so auswirken, dass religiöse Homogenitätszwänge im Innern einer konfessionellen Ordnung

fügt er den Verlust von Herausgehobenheit gegenüber den Anderen und deren Vergesellschaftungsformen hinzu.

9 Eines dieser Risiken besteht darin, dass die Formen der Produktion von Pluralisierungssachverhalten undeutlich bleiben.

10) Zur neueren Diskussion vgl. etwa Kaspar v. Greyerz [u. a.] (Hgg.), Interkonfessionalität - Transkonfessionalität - binnenkonfessionelle Pluralitä. Neue Forschungen zur Konfessionalisiemungsthese, (iütersloh 200)3 (Schriften des Vercins für Reformationsgeschichte 201), und Harm Klueting, Zwoite Reformations -Konfessionsbildung - Konfessionalisierung. Zwanzig Jahre Kontroversen und Frgebnisse nach zwanzig Jahren, in: Historische Zoitschifift 277 (2003), \$. 309)341. - Die Ausdrucke, Konfession<, , Konfessionalitä, , Konfessionalismus< werden im Folgenden mangels besserer verwendet, obwohl sie freilich ihrerseits asymmetrisch sind: Das Katholische ist in katholischer Perspektive selbstverständlich gerade nichts Konfessionelles. Hierzu im Uberblick Carl Ileinz Rat schow, [Art.] Konfession/Konfessionalitate, in: Theologische Realenzyklopaidie, Bal. 19) (1990), S. $419-4: 26$.

11 Zur Theorie solcher Invisibilisierungsstrukturen vgl. Karl-Sieghert Rehberg, IDit' , Offentlichkeit der Institutionen. Grundbegrifliche Ïberlegungen im Rahmen der Theorie und Analyse' institutioneller Mechanismen, in: Gerhard (iohler (Hg.), Macht der offentlichkeit -- Öfentlichkeit der Marht, Baden-Barlen 1995, S. 181 211 , hier hes. S. $196 \mathrm{ff}$; ders. [Anm. :3], s. 9ff. 
anwachsen, während nach außen hin eher Differenzdramatisierungen wahrscheinlich werden. Dann aber werden Weltauslegungen nach dem Negationsschema von >Norm und Abweichung`, `Gültigkeit und Nichtigkeit gerade restabilisiert, ${ }^{12}$ etablieren sich neue, aber leistungsfähige asymmetrische Gegenbegriffe. ${ }^{13}$ Insofern könnte Konfessionalität geradezu als Modus der Abarbeitung und Disziplinierung von Pluralisierungserfahrungen bezeichnet werden.

Im Folgenden versuche ich solche Überlegungen anhand einer kleinen Geschichte zu konkretisieren, in welcher von Verhandlungen über Reliquien und deren religiös-magischen Gebrauch erzählt wird. Die Texte, welche diese Geschichte erzählen, entstammen dem reichen Archiv deutscher Prosaschwänke des 16. Jahrhunderts, ${ }^{14}$ und zeigen will ich an ihrem Beispiel, wie Normkonflikte aus dem Zentrum der frühneuzeitlichen Religions- und Frömmigkeitshistorie durch konfessionelle Dramatisierung gebändigt oder im Gegenteil erzählerisch in der Weise entbunden werden können, dass sich darin religiöse >Pluralisierung in dem hier vorausgesetzten Sinne zu manifestieren scheint: eine epistemische Irritationserfahrung, die gewissermaßen stiefer liegt als konfessionelle Differenzierung.

Damit setze ich übrigens voraus, dass Erzählen sich als eine Wissensform auffassen lässt: als eine Form der Produktion, Speicherung und Reproduktion kollektiven Wissens (auf der Ebene des Erzählten) wie desjenigen, was kulturell jeweils als Wissensorganisationswissen zur Verfügung steht (auf der Ebene der Strukturen, Muster, Schemata des Erzählens). Unter dieser Voraussetzung ließe sich speziell das >niedere`Erzählen des 16. Jahrhunderts versuchsweise auffassen als eine Kommunikationsordnung, innerhalb derer im Spannungsfeld institutionalisierter narrativer Gestaltungsformen $^{15}$ einerseits und epistemischer Möglichkeiten und Herausforderungen andererseits Pluralisierungs- und Kontingenzerfahrun-

12. Ein Begriff vou Luhmann (Niklas luhmann, Die Gesellschaft der Gesellschaft, 2 Bde., Frankfurt/M. 1997, Kap. 3 |»Evolution «], bes. S. 425-428 u. 485-505).

1:3 So erkennt beispielsweise die lutherische Polemik im Papst den Teufel oder Antichrist, in Papsttum das Reich der Finsternis, im alten Glauben einen heidnischen und algöttischen. Aus entgegengesetzter Perspektive erscheint Luther als aus der Arche ent flogener schwarzer Rabe, als Narr oder Ketzer, und es steht der sallgemeinen christlichen Kirche die sSekte` der Lutheraner gegenüber, beim Jiingsten Gericht den rechtgläubigen Schäflein die zur Verdammonis bestimmten liorekr usw.

1.1 Zur Forschungslage vgl. dic Thersicht von Peter C. M. Dieckow, Un jetzt der "Katzenborischen art Rollwagenbicher« zu gedenken - Zur Erforschung deutschsprachiger Prosacrzählsammlumgen aus der zwoiten Hälfte des 16. Jahrhunderts, in: Euphorion $90(1996)$, S. $7(i-1: 33$.

15 Vgl. Wilhelm Volskamp, ('attungen als literarise-h-soziale Institutionen. (Zu Problemen sozial- und funktionsgeschichtlich orienticrter Gattungstheorie und -his torio), in: Walter Ilinck (Hg.), 'lextsortenlehre - Gattungsgeschichte, Heidelberg 1977 (Mediun Literatur 4), s. $27-44$. 
gen - in dem eben skizzierten Sinne - sowohl produziert wie zugleich kulturell verarbeitet werden können. Dies ist freilich eine Hypothese jenseits der Grenzen des gegenwärtigen Versuchs. In ihm geht es lediglich um einzelne Beispiele für die Eindämmung beziehungsweise die Exposition von Normalternativen, Kontingenzen, Orientiertheitsverlusten. Beginnen aber will ich mit Beobachtungen zu einem Text, der die nämliche Geschichte in der Form einer Fazetie bietet, und das heißt: so erzählt, dass es überhaupt nicht auf die Kollision von Normen als solche ankommt, sondern auf die witzige Pointe im Diskurs über sie.

\section{Pointierung: `Geschwenck Henrici Bebelij}

Es sind Texte aus den 1557 und 1563 publizierten Prosaerzählsammlungen `Gartengesellschaft , und >Wendunmuth von Jakob Frey und Hans Wilhelm Kirchhof, die hier im Mittelpunkt stehen sollen. Erstmals freilich begegnet die in ihnen erzählte Geschichte, soweit ich sie zurückverfolgen kann, ein halbes Jahrhundert früer in dem aus dem Jahre 1508 stammenden Erstdruck des ersten Teils der $>$ Facetiae $<$ des Tübinger Lektors in oratoria moralibus oder poetrij ${ }^{16}$ Heinrich Bebel im Rahmen seiner >Opuscula

${ }^{16}$ Rudolf v. Roth, Urkunden zur Geschichte der Universität Tübingen aus den Jahren 1476 bis 1550, Tübingen 1877, S. 85. Vgl. zum Autor bes.: [Kar] Philipp] Conz, [Art.] >Bebel (Heinrich)<, in: J. S. Ersch, J. G. Gruber (Hgg.), Allgemeine Encyclopädie der Wissenschaften und Künste, Bd. V/8 (1822), S. 274-280; Elfriede MoserRath, [Art..] >Bebel, Heinrich<, in: Enzyklopädie des Märchens, Bd. 2 (1979), Sp. 6-15; Helmuth Kiesel, [Art.] Bebel, Heinrich<, in: Literaturlexikon. Autoren und Werke deutscher Sprache, hg. v. Walther Killy, Bd. 1, Gütersloh, München 1988, S. 360 -362; Klaus Graf, [Art.] >Heinrich Bebelk, in: Stephan Füssel (Hg.), Deutsche Dichter der fruhen Neuzeit (1450-1600). Ihr Leben und Werk, Berlin 1993, S. 281-295; Carl Joachim Classen, Zu Heinrich Bebels Leben und Schriften, Göttingen 1997 (Nachrichten der Akademie der Wissenschaften in Goittingen, I. Philologisch-historische Klasse 1997/1); Wilhelm Kuhlmam, Heinrich Bebel, in: Humanistische Lyrik des 16. Jahrhunderts, hg. v. W. K., Frankfurt/M. 1997 (Bibliothek deutscher Klassiker 146; Bibliothek der Frühen Neuzeit 5), S. 10651069; Klaus Graf, Heinrich Bebel (1472-1518). Wider ein barbarisches Latein, in: Paul Gerhard Schmidt (Hg.), Humanismus im deutschen Südwesten. Biographische I'rofile, 2., veränd. Aufl.. Stutgart 2000, S. 179-194; Dieter Mertens, [Art.] >Bebel, Heinriche, in: Deutscher Iumanismus 1480-1520. Verfasserlexikon, hg. v. Franz Josef Worstbrock, Bol. 1/1, Berlin, New York 2005, Sp. 142-16;3; zu den ,Facetiaes: Stroszeck [Anm. 2], S. 8:3-103; Joel Lefebvre, Les > Facetiace de Heinrich Bebel, in: Reforme, llumanisme, Renaissance 4 (1978), H. 7, s. 3640) Bamer [Anm. 2], S. $119 \mathrm{ff}$; Anna Mühlherr, Fazete Gewitztheit - Witz der Fazetie, in: Walter Haug, Burghart Wachinger (Hgg.), Kleinstformen der Literatur, Tübingen 1994 (Fortuna vitrea 14), \$, 235-246; Volker Honemann, Heinrich Bebel und seine Fazetien, in: ders., Tomas Tomasek (IIgg.), Germanistische Mediävistik, Münster 1969) (Münsteraner Finführungen: Germanistik 4), S. 255276; Frank Witchow, Eine Frage der Ehre: Das Problem des aggressiven Sprechakts in den Facetien Bebels, Mulings, Frischlins und Melanders, in: Zf( 11 (2001), \$. 3:36 -360. 7u druckgeschichtlichen I )aten vgl. die Website des von I) 
novar. Von hier aus versuche ich den Problemzusammenhang zu erschließen. Um allerdings für die nachfolgenden Vergleichungen den Eindruck etwelcher entwicklungsgeschichtlicher Verlaufsfiguren, sie seien historischer, intellektueller oder sprachlicher Art, zu vermeiden, spreche ich von Bebels Fazetie anhand ihrer weitgehend getreuen, anonymen deutschen Übersetzung in den 1558 erstmals gedruckten 'Geschwenck Henrici Bebelij.${ }^{17}$ Die relative Synchronie der Texte mag dann zudem deutlich werden lassen, dass es sich im Folgenden keineswegs um irgendeine historische Entwicklungs-, sondern um eine systematische Modellreihe handelt. Sie will in der erzählerischen Arbeit an einem `plot` so etwas wie die systematische Ungleichzeitigkeit des historisch Gleichzeitigen hervortreten lassen.

Die Erzählung, um die es geht, gehört zu einer kleinen Gruppe fazetuöser Geschichten über einen Priester mir wol bekannt/mit namen. ${ }^{18}$ Fisi-

ter Mertens geleiteten Projekts eines Schriftenverzeichnisses von Heinrich Bebel: <http://www.histsem.uni-freiburg.de/heinrich-bebel/>.

17 Die Geschwenck Henrici Bebelij / welcher von Keiser Maximiliano ist zü einem Poeten gekrónt worden. Jn drey bucher getheilet/ gebessert vnnd gemehrt. Sampt einer Practica vnd Vorzeichen zükünfftiger ding / so biß auff den Jüngsten tag vnder den menschen gemein sein werden. Durch ein güten Gesellen auß Latein in das Teüsch gebracht. Getruckt im Jar / Anno M.D.LVII [1558]. Exemplar: BSB München: L.eleg.m. 111 c [VD 16: B 1222]. Die deutsche Übersetzung basiert nicht auf dem 1508 bzw. 1512 zuerst publizierten Text der >Facetiae،, sondern auf einer 1542 in Tübingen erscheinenden, leicht modifizierten Ausgabe (Lefebvre [Anm. 16]); vgl. zur Übersetzung der >Facetiae< auch Paul Antony, Studien zu Heinrich Bebels Facetiae und ihren Übersetzungen, in: Jochen Möckelmann (Hg.), Sprache und Sprachhandeln. Fs. für Gustav Bebermeyer zum 80. Geburtstag am 16. 10. 1970, Hildesheim, New York 1974, S. 89-114, und Johannes Klaus Kipf, Zwischen Wiedererzählen und Übersetzung. Übertragungen frühneuhochdeutscher Schwänke in neulateinische Fazetien und umgekehrt im Vergleich, in: Britta Bußmann [u.a.] (Hgg.), Übertragungen. Formen und Konzepte von Reproduktion in Mittelalter und Früher Neuzeit, Berlin, New York 2005 (Trends in Medieval Philology 5), S. 219-251.

18 Die Geschwenck Henrici Bebelij< [Anm. 17], fol. D viir ${ }^{r}$ In Bebels lateinischem Text (Heinrich Bebels Facelien. Drei Bücher. Historisch-kritische Ausgabe, hg. v. Gustav Bebermeyer, Leipzig 1931 [Bibliothek des literarischen Vereins in Stuttgart 276], 1. 59, S. 26): Sacerdos quidam notissimus, nomine Fysilinus. - Eine historische oder literarische Figur dieses Namens, auf die Bebel zurükgegriffen haben könnte, vermag ich nicht nachzuweisen. In einer anderen Version einer weiteren Geschichte (I. 63) aus der Fisilinus-Gruppe, welche in der vimmerischen Chronik begegnet, heißt der Protagonist Martin Vischer (vgl. Heinrich Bebols Schwänke. Zum ersten Male in vollständiger Übertragung, hg. v. Albert Wesselski, 2 Bde., München, Leipzig 1907, Bd. 1, S. 144f.). Der vage Namensanklang führt aber nicht über das bereits in Wesselskis Kommentar zur betreffenden Fazetie gesetzte Fragezeichen hinaus (ebd., S. 144: "Vischerlin = Fysilin? «). Aıch die Namensähnlichkeit mit einem im dritten Buch der Bebelschen >Facetiace zweimal genamnten Georg Weselin (im Druck von 1512: Vueselin) ist wohl cher zufaillig, lässt jedenfalls keine Rückschlüsse auf historisch-biographische Hintergründe der Fisilinus-(Geschichten zu. Nähme man dagegen an, dass es sich um einen sprechenden Namen handelte, dann könnte der Blick auf eine ganze Reihe lateinisch-romanischer oler auch deutscher Lexeme fallen, ohne dass al- 
linus, so lautet dieser Name, macht sich unter anderem auch - etlich Heiligthum $b^{19}$ mit sich führend - als Wanderprediger auf, um von den Bauem großen Besitz einzuheimsen. Dies gelingt ihm, da es sich um Pestzeiten handelt, vermittels des Versprechens, wer immer die Reliquien küsse, bleibe das Jahr über von der Seuche verschont. Ein gelehrter Doktor hingegen kritisiert Fisilinus und seine Ausnutzung etablierter Reliquienpraxis: [...] er solte so gar greifflich fál nit fürbringen/ noch das Volck zu falschem glauben bewegen / oder wo er doch sollich wenen und traum her hette. ${ }^{20}$ Fisilinus aber antwortet prompt: Keineswegs liuge er, die Berührung der Reliquien schütze vor der Pest, doch küssten die Bauern ja gar nicht die Reliquie, sondern allein das Glas der Monstranz. Überhaupt lasse er die Bauren ehe den Teüfel hinfuren/dann sie mir solten mein Heiligthumb kussen. ${ }^{21}$

Dies ist die pointierteste Fassung jener Geschichte, um die es im Folgenden geht und die freilich auf einer ganzen Reihe kultureller Plausibilitäten und literarischer Voraussetzungen operiert, die ich unter den Stichworten >Reliquie $<$ und >Reliquienbetrugserzählungen $<$ lediglich kurz andeuten kann.

Einerseits also die $>$ Reliquies: Sie stellt die totale und vermittlungslose Präsenz desjenigen Heils in einer dauerhaften Form her, welches im Heiligen manifest geworden war und offenbart wurde im Prozess seiner Gottverähnlichung. ${ }^{22}$ In ihr ist also der Heilige und das Heil real und ganz

lerdings eine semantisch funktionale etymologische Zuordnung mit hinreichender Plausibilität zu rekonstruieren wäre. Denkbar wären etwa Anklänge an mlat. fiscalinus/fiscilinus/fisgilinus (dem Fiskus dienend) oder an diminutive mittelalterliche und frühneuzeitliche Abkömmlinge von lat. fusus: mlat. fusillus/fusellus (Spindel, Zapfen), davon afrz. fusel/fuisselfuisol (Zapfen; auch als Ausdruck eines minimalen Werts gebraucht); vgl. auch mhd./fruhnhd. visel/fisel (Penis), dessen Verkleinerungsform tisellim allerdings im Grimmschen Wöterbuch ebenso wie in den mittelhochdeutschen Lexika nur durch eine einzige Stelle im $>$ Parzival< belegt wird $(112,25)$.

19 , Die Geschwenck Ilenrici Bebelij, [Anm. 17], fol. I) viiiv; Bebol, Facetien [Anm. 18], I. 62, S. 27: quasdam reliquias sanciorum.

20, Die Geschwenck Henrici Bebelij [Anm. 17], fol. I) viiiv; Bebel Facetien [Anm. 18], I. 62, S. 27: ne haes tam absona dicene aut plebem ad falsam credulitatem induceret aut unde hane vanam pensasiomem haurivel.

21 , Die Geschwenck Henrici Bebelije [Anm. 17], fol. 1) viii"; Bobel, Faceticn [Anm. 18], I. 62, S. 27: sinerem enim rusticos (ul cius verbis loguar) diabolo devoveri, anleguam mihi oscalarentur reliquias meas.

2.2. Sowenig wie das leil und die Gnade selbst, die in ihnen verköpert und real präsent sind, mijssen also Roliquien der Logik von Tejl und (ianzem (vgl. Ialt mann |Anm. 12], \$. 912-931) unterliegen. Dies wird insbesondere an der Frage der Reliquienteilung theolegisch alsgearbeitet; vgl. Renate v. Dobschuitz, [Art.] - Reliquiene, in: Lexikon der christlichen Ikonographie, Bol. :3 (1971), Sp. 5:38 . 546, hier S. 5:38; Arnold Angenendt, corpus incorruptum. Fine lecitidece der mitfelasterlichen Reliquienverehrung, in: Saeculum 42 (1991), s. 320--348; ders., Zur E,hre der Altäre erhoben. Zugleich ein Beitrag zur Reliquienteilung, irs: Römische 
substanziell präsent, mit ihr ragt Transzendenz direkt und konkret in die Immanenz herein, ${ }^{23}$ und darum ist ihr vor allem eine sinnliche Praxis angemessen: ${ }^{24}$ das Geblendetsein von göttlichem Glanz, das Riechen des süßen Geruchs der Heiligkeit, die körperliche Berührung der Reliquie. Diese Prinzipien von Heiligenkult und Reliquienfrömmigkeit werden nach einer mehr als tausendjährigen, in sich ungemein vielfältigen Geschichte insbesondere auf dem 4. Laterankonzil 1215 in die für die Kirche des Spätmittelalters und der Frühen Neuzeit verbindliche Form gebracht. Zu dieser Form gehören auch das Kanonisationsverfahren, die Voraussetzung päpstlicher oder bischöflicher Approbation für die Reliquie sowie eine Frömmigkeitspraxis, die sich im Anschauen oder Berühren des in der Reliquie gegenwärtigen Heils versichert weiß. ${ }^{25}$

Daneben war in der theologischen Tradition freilich auch schon im Mittelalter die epistemische Möglichkeit gegeben, magischen Reliquiengebrauch kritisch distanziert beurteilen zu können. ${ }^{26}$ In den Diskursen von Humanismus und Reformation wird die theologische Begründungsfähigkeit solcher Praxis dann überhaupt prekär (womit über die kulturelle Per-

Quartalschrift für christliche Altertumskunde und Kirchengeschichte 89 (1994), S. 221-244, hier S. 237 ff.; ders., Heilige und Reliquien. Die Geschichte ihres Kultes vom frühen Christentum bis zur Gegenwart, München 1994, S. 149-166; Anton Legner, Reliquien in Kunst und Kult. Zwischen Antike und Aufklärung, Darmstadt 1995, S. $6 \mathrm{f}$.

23 Vgl. Peter Dinzelbachor, Die ,Realpräsenz der Heiligen in ihren Reliquiaren und Gräbern nach mittelalterlichen Quellen, in: ders., Dieter R. Bauer (Hgg.), Heiligenverehrung in Geschichte und Gegenwart, Ostfildern 1990, S. 115-174, und Luigi Canetti, Frammenti di eternità. Corpi e reliquie tra antichità e medioevo, Rom 2002 (sacro/santo [nuova seric] 6).

2.1 Vgl. Hans Illrich Gumbrecht, Das Nicht-Hermeneutische. Skizze einer Genealogie, in: Jijrg Huber, Alois Martin Müller (Hgg.), Die Wiederkehr des Anderen. Interventionen, Basel, Frankfurt/M. 1996 (Interventionen 5), S. 17-35.

25) Ifeinrich Denzinger, Enchíridion symbolorum definitionum et declarationum de rebus fidei et morum - Kompendium der Glaubensbekenntnisse und kirchlichen Lehrentscheidungen, hg. v. Poter Hünermann, 40. Aufl., Freiburg [u.a.] 2005, Nr. 818; vgl. zur Interpretationsgeschichte der einschlägigen Bestimmungen Christof I. I Diedrichs, Vom Glauben zum Sehen. Die Sichtbarkeit der Reliquie in Reliquiar. Fin Beitrag zurr Geschichte des Sehens, Berlin 2001, S. 10 ff.; Angenendt, Heilige und Reliquien [Anm. 22], bes. S. $149 \mathrm{ff}$.

26) Vgl. Klaus Guth, Guibert von Nogent und die hochmittelalterliche Kritik an der Reliquienverehrung, Augsburg 1970 (Studien und Mitteilungen zur Geschichte des Benediktinerordens und seiner Zweige, Ergänzungsbd. 21); Henri Platelle, Guibert de Nogent et le $>$ be pignoribus sanctorum<. Richesses et limites d'une critique médiévale des reliques, in: Edina Bozóky, Anne-Marie Helvétius (Hgg.), las reliques. Objets, cultes, symboles. Actes du colloque international de l'Université du Littoral-cote d'opale (Boulogne-sur-Mer) 4-6 septembre 1997, Turnhout 1999 (Jagiologia 1), \$. $109-121$; J. C. Szirmai, Les soraies de saint Francois. Critique médiévale de la vénération des reliques. Une approche socio-culturelle et littéraire, in: Nederlands archief voor kerkgeschiedenis 79 (1999), S. $226-24: 3$ 
sistenz magisch-reliquiärer Handlungen selbst noch gar nichts gesagt ist ${ }^{27}$ ): alles tod ding heißt es so bündig wie abschließend in Luthers >GroBem Katechismus $<$ über die Reliquien, ${ }^{28}$ die einschlägigen reformatorischtheologischen Argumente fasst die >Confessio Augustana< wie folgt zusammen: Aus der Heiligen Schrift läßt sich aber nicht beweisen, daß man die Heiligen anrufen oder Hilfe bei ihnen suchen soll. "Denn es ist nur ein Gott und nur ein Mittler zwischen Gott und den Menschen, nämlich der Mensch Christus Jesus « [1. Tim. 2,5]. ${ }^{29}$ Umgekehrt wird im Prozess der Konfessionsbildung an der Zulässigkeit und Nützlichkeit von Reliquienkulten in der katholischen Kirche festgehalten: Im Prinzip ganz auf der seit dem 4. Lateranum verfolgten Linie sanktioniert das Tridentinum in seiner XXV. Sitzung am 3. Dezember $1563 \mathrm{im}$ >Decretum de invocatione, veneratione et reliquiis Sanctorum, et sacris imaginibus< die überkommenen religiösen Praxisformen. ${ }^{30}$

27 Vgl. etwa Richard van Dülmen, Volksfrömmigkeit und konfessionelles Christentum im 16. und 17. Jahrhundert, in: Wolfgang Schieder (Hg.), Volksreligiosität in der modemen Sozialgeschichte, Göttingen 1986 (Geschichte und Gesellschaft, Sonderh. 11), S. 14-30; Rebekka Habermas, Wunder, Wunderliches, Wunderbares. Zur Profanierung eines Deutungsmusters in der frühen Neuzeit, in: Richard van Dülmen (Hg.), Armut, Liebe, Ehre. Studien zur historischen Kulturforschung, Frankfurt/M. 1988, S. 38-66; Marc Venard, Volksfrömmigkeit und Konfessionalisierung, in: Wolfgang Reinhard, Heinz Schilling (Hgg.), Die katholische Konfessionalisierung, Münster 1995 (Reformationsgeschichtliche Studien und Texte 135), S. 258-270.

28 Martin Luther, Werke. Kritische Gesamtausgabe (Weimarer Ausgabe), Bd. 30, Erste Abt., Weimar 1910, S. 145, Z. 19 (im Rahmen der Auslegung des dritten Gebotes). Zur theologischen Kontroverse verweise ich lediglich auf Peter Manns, Luther und die Heiligen, in: Remigius Bäumer (Hg.), Reformatio Ecclesiae. Beiträge zu kirchlichen Reformbemühungen von der Alten Kirche bis zur Neuzeit. Festgabe für Erwin Iserloh, Paderborn [u.a.] 1980, S. 535-580; Frieder Schulz, [Art.] >Heilige/Heiligenverehrung VI. Die protestantischen Kirchen`, in: Theologische Realenzyklopädie, Bd. 14 (1985), S. 664-672; Stéphane Boiron, La controverse née de la querelle des reliques à l'époque du concile de Trente (1500-1640), Paris 1989 (Travaux et recherches de l'Université de Droit d'Économie et de Sciences Sociales de Paris. Série Sciences Historiques 28); Legner [Anm. 22], S. 325-342; Alain Joblin, Lattitude des protestants face aux reliques, in: Bozóky/Helvétius [Anm. 26], S. 123-141.

29 Das Augsburger Bekenntris Deutsch 1530-1980. Revidierter Text, hg. v. Günther Gaßmann, 6. Aufl., Göttingen 1988, Art. 21 (»Über die Heiligenverehrung«), S. 37; vgl. dazu Peter Manns, Die Heiligenverehrung nach CA 21, in: Erwín Iserloh, Barbara Hallensleben (Hgg.), Confessio Augustana und Confutatio. Der Augsburger Reichstag 1530 und die Einheit der Kirche. Internationales Symposion der Gesellschaft zur Herausgabe des Corpus Catholicorum in Augsburg vom 3.7. September 1979, Münster 1980 (Reformationsgeschichtliche Studien und Texte 118), S. 596-651.

:30 Denzinger, Enchiridion symbolorum [Anm. 25], Nr. 1821-1825, hier Nr. 1822 und 1825; vgl. allgemein Hubert Jedin, Entstehung und Tragweite des Trienter Dekrets über die Bilderverehrung, in: ders., Kirche des Glaubens - Kirche der Geschichte. Ausgewählte Aufsätze und Vorträge, Bd. 2: Konzil und Kirchenre- 
Zum zweiten exkursorischen Stichwort: Geschichten von der Fälschung oder vom betrügerischen Gebrauch von Reliquien etwa durch listig-verschlagene Geistliche begegnen in der deutschen Literatur spätestens seit des Strickers Schwankroman vom Pfaffen Amis; dort in einer Episode, die bis zum >Ulenspiegel hin literarisch produktiv bleibt. ${ }^{31} \mathrm{Im}$ Spätmittelalter und in der Frühen Neuzeit avancieren, wie es scheint, derartige Reliquienbetrugserzählungen überhaupt zu einem der Standardfälle fazetuöser und schwankhafter Sujets. Und selbstverständlich liegt es nahe, diese Konjunktur ${ }^{32}$ damit in Zusammenhang zu bringen, dass einerseits dieses Sujet

form, Freiburg/Br. [u.a.] 1966, S. 460-498; Heribert Smolinsky, Reformation und Bildersturm. Hieronymus Emsers Schrift gegen Karlstadt iber die Bilderverenrung, in: Bäumer [Anm. 28], S. 427-440; Angenendt, Heilige und Reliquien [Anm. 22], S. 242-256.

31 Der Stricker, Der Pfaffe Amis. Mittelhochdeutsch/Neuhochdeutsch, hg. v. Michael Schilling, Stuttgart 1994 (RUB 658), V. 335-495; vgl. dazu Stephen L. Wailes, Studien zur Kleindichtung des Stricker, Berlin 1981 (PhStQ 104), S. 231 ff.; Ein kurtzweilig Lesen von Dil Ulenspiegel. Nach dem Druck von 1515 mit 87 Holzschnitten, hg. v. Wolfgang Lindow. Bibliographisch ergänzte Ausgabe, Stuttgart 2001 (RUB 1687), cap. 31, S. $92 \mathrm{ff}$.

32 Am bekanntesten sind Giovanni Boccaccio, Decameron, hg. v. Vittore Branca, Mailand 1985, VI 10, S. 539-548, und Geoffrey Chaucer, The Canterbury Tales, in: The Riverside Chaucer, 3. Aufl., hg. v. Larry D. Benson, Oxford, New York 1988, S. 1-328, hier S. 194 ff. (»The Pardoner's Prologue«); daneben unter anderem: Das Ambraser Liederbuch vom Jahre 1582, hg. v. Joseph Bergmann, Stuttgart 1845 (Bibliothek des literarischen Vereins in Stuttgart 12), S. 164 f., Nr. CXXXVI; Sebastian Brant, Das Narrenschiff, hg. v. Manfred Lemmer, 4., erw. Aufl., Tübingen 2004 (Neudrucke deutscher Literaturwerke N. F. 5), S. 154, cap. 63, V. $11-$ 21; Henri Estienne, Apologie pour Hérodote. Satire de la société au XVI ${ }^{\mathrm{e}}$ siècle. Nouvelle édition faite sur la première et augmentée de remarques, hg. v. $P$. Ristelhuber, Bd. 2, Genf 1969 [zuerst Paris 1879], S. 305f. u. 408-413; Johann Fischart, Sämtliche Werke, hg. v. Ulrich Seelbach [u. a.], Bd. 2: Eulenspiegel reimenweis. Bearbeitet von U. S. u. W. Eckehart Spengler, Stuttgart-Bad Cannstatt 2002 (Berliner Ausgaben), S. 142-146, cap. XXX; Jakob Freys Gartengesellschaft (1556), hg. v. Johannes Bolte, Tübingen 1896 (Bibliothek des litterarischen Vereins in Stuttgart 209), S. 49 f., Nr. 34 (vgl. unten, S. 458-463), S. 95 f., Nr. 81 (vgl. unten, S. 465 f.), und S. $102 \mathrm{ff}$., Nr. 87; Hans Wilhelm Kirchhof, Wendunmuth, hg. v. Hermann Ósterley, 5 Bde., Tübingen 1869 (Bibliothek des litterarischen Vereins in Stuttgart 95-99) [Repr. Hildesheim, New York 1980], Bd. 1, S. 538 ff., Nr. I $2.75-$ 2.78 (vgl. unten, S. 453-457); Bd. 2, S. 148-151, Nr. II 99 f. (vgl. unten S. 464 f.); Bd. 3, S. 310 f., Nr. V 36, und S. 316 f., Nr. V 47; Martin Luther, Werke. Kritische Gesamtausgabe (Weimarer Ausgabe). Tischreden, Bd. 2: Tischreden aus den dreißiger Jahren, Weimar 1913, S. 447f., Nr. 2399, u. S. 569 f., Nr. 2638; Philipp Melanchthon, Responsio [...] Ad Scriptum quorundam delectorum a Clero Secundario Coloniae Agrippinae [1543], in: ders., Werke in Auswahl, Bd. 6: Bekenntnisse und kleine Lehrschriften, hg. v. Robert Stupperich, Gutersloh 1955, S. 381-421, hier S. 400f.; Martin Montanus, Das Ander theyl der Garten gesellschafft, in: ders., Schwankbücher $(1557-1566)$, hg. v. Johannes Bolte, Tübingen 1899 (Bibliothek des litterarischen Vereins in Stuttgart 217), S. 253-434, hier S. $404 \mathrm{f}$, cap. 104; Hans Sachs, Sämtliche Fabeln und Schwänke in chronologischer Ordnung nach den Originalen, hg. v. Edmund Goetze, Bd. 2, Halle 1894 (Neudrucke deutscher Litteraturwerke des XVI. und XVII. Jahrhunderts 126- 
als Medium von diskursiven Verhandlungen der für alle Theologie und religiöse Praxis zentralen Grenzen von Immanenz und Transzendenz geeignet schien und dass andererseits spätestens mit der Reformation »die Verehrung der Heiligen und Reliquien zum Kampfthema geriet. $^{33}$ Doch bedeutet dies freilich nicht, alle solchen Erzählungen verstünden sich erst und schon im Horizont konfessioneller Auseinandersetzungen. Im Folgenden soll, wie angedeutet, vielmehr gezeigt werden, dass sich in ihnen vielleicht: im Einzelfall - auch solche Formen religiöser Pluralisierung manifestieren können, die jenseits konfessioneller Bändigung bleiben.

Vor diesem Hintergrund lässt sich jetzt zu Bebels Fazetie zurückkehren. Sie setzt Wissens- und Erzähltraditionen, wie sie hier angedeutet wurden, voraus. $\mathrm{Zu}$ ihren Voraussetzungen gehören zugleich auch die Rollenklischees und Aktionsschemata schwankhafter Betrügereien, die in konventionsgerechten sozialen Hierarchien und kognitiven Asymmetrien zwischen den Betrogenen und dem Betrüger manifest sind. ${ }^{34}$ Doch ist all dies nur das Material der Fazetie. Ihre Pointe liegt nicht im Handlungszusammenhang von Priester und Bauem, sondern im Konversationszusammen-

134), S. 57-60, Nr. 217, u. S. 485-488, Nr. 337; Hans Sachs, Sämtliche Fabeln und Schwänke in chronologischer Ordnung nach den Originalen, Bd. 3: Die Fabeln und Schwänke in den Meistergesängen, hg. v. Edmund Goetze u. Carl Drescher, Halle 1900 (Neudrucke deutscher Litteraturwerke des XVI. und XVII. Jahrhunderts 164-169), S. 248f., Nr. 117; Hans Sachs, Sämtliche Fabeln und Schwänke, Bd. 4: Die Fabeln und Schwänke in den Meistergesängen, hg. v. Edmund Goetze 11. Carl Drescher, Halle 1903 (Neudrucke deutscher Litteraturwerke des XVI. und XVII. Jahrhunderts 193-199), S. 66f., Nr. 280; Hans Sachs, Sämtliche Fabeln und Schwänke. In chronologischer Ordnung nach den Originalen, hg. v. Edmund Goetze, 2. Aufl. besorgt v. Hans Lothar Markschies, Bd. 1, Halle 1953 (Neudrucke deutscher Literaturwerke des XVI. und XVII. Jahrhunderts $110-117$ ), S. 185 ff., Nr. 61; Hans Sachs, [Werke,] hg. v. Adelbert von Keller u. Edmund Goetze, Bd. 17, Hildesheim 1964 [zuerst Stuttgart 1888 (Bibliothek des Litterarischen Vereins in Stuttgart 181)], S. 355-360; dramatische Variationen des Themas: Le pardonneur, le triacleur et la tavernière, in: Recueil de farces (1450-1550). Textes annotés et commentés, hg. v. André Tissier, Bd. 5, Genf 1989 (Textes littéraires français 374), S. 231-273; Johannes Reuchlin, Comoedia cui nomen Sergius, Erfurt: Wolfgang Schenck 1504 [VD 16: R 1283]; Niklaus Manuel, Der Ablasskrämer [1525], in: ders., Werke und Briefe. Vollständige Neuedition, hg. v. Paul Zinsli u. Thomas Hengartner, Bern 1999, S. 255-283. Vgl. generell Szirmai [Anm. 26], S. 235-243; außerdem die Eintrage K 1865 und K $1976 \mathrm{im}$ >Motif-Index<, die Hinweise auf verwandte Erzählungen in Wesselskis Kommentar zu den FisilinusGeschichten (Bebel, Schwänke [Anm. 18], Bd, 1, S. 142-146), in Boltes Anmerkungen zur >Gartengesellschaft ([Anm. 32], S. 228, 245f. u. 248) und zu deren Ander theyl (Montanus [Anm. 32], S. 628) sowie die Belege bei Ernst Heinrich Rehermann, Das Predigtexempel bei protestantischen Theologen des 16. und 17. Jahrhunderts, Göttingen 1977 (Schriften zur niederdeutschen Volkskunde 8), S. 172 , Nr. 110 (»Eselsfüße als Heiligtümer «).

:3:3 Angenendt, Heilige und Reliquien [Anm. 22], S. 243.

:34 Vgl. Peter Strohschneider, [Art.] SSchwank<, in: Literaturlexikon. Begriffe, Realien und Methoden, hg. v. Walther Killy u. Volker Meid, Bd. 14, Gütersloh, München 1993, S. $354-355$. 
hang von Priester und Gelehrtem. Dieser zweite ist mit jenem ersten Teil des kleinen Textes indes weder kausal noch motivational noch strukturell gekoppelt. Die völlig kontingent einsetzende Konversation der Gebildeten kommt in der Welt der Bauern nicht vor, diese und die in ihr situierte Reliquienpraxis spielen in der Konversation allein als Referenz eine Rolle. Wichtig sind offenkundig nicht schwankhafte Handlungsfunktionen und >plot<-Strukturen, sondern es entscheidet jene gewitzte Schlagfertigkeit, mit welcher Fisilinus die gelehrte Kritik an seiner Reliquienpraxis spontan abwehrt. Ziel und Witz des Erzählens liegen im facete dictum, in der fein füglich $^{35}$ vorgetragenen, witzigen - und so den andern zum Schweigen bringenden - Äußerung. ${ }^{36}$ Witzig aber ist diese Äußerung darin, dass sie die gelehrte Kritik zurückweist, indem sie die Richtung ihres Diskurses so überraschend wie raffiniert umkehrt. Der Doktor hatte die magische Reliquienpraxis als Beförderung von Aberglauben verurteilt. Fisilinus setzt dagegen, die Heilswirkung der Reliquie sei gewiss, doch hätten die Bauern an ihr gar keinen Anteil, weil sie allein mit der Monstranz in Berührung kämen. Mit dieser Einführung der kategorialen Differenz zwischen Reliquie und Reliquiar ist zugleich ein sozialständischer Unterschied etabliert. An die Stelle einer Wissensasymmetrie (die Wissenden gegenüber dem leichtgläubig magischer Praxis vertrauenden Volk) tritt eine Ständeasymmetrie (Priester und Akademiker gegenüber den Bauem). Ihr indes unterliegt ein Code von Reinheit und Unreinheit, ${ }^{37}$ mit dem sich zugleich das Devalorisierungsrisiko verschiebt. Das Riskante an der Reliquienpraxis scheint im facete dictum des Fisilinus nicht darin zu bestehen, dass die Bauern durch Magie verführt, sondern darin, dass die Reliquien durch die Bauern befleckt werden könnten. Der Schutz des Sakralen vor Profanierung aber ist in der gegebenen Wissensordnung selbstverständlich weit wichtiger als der Schutz der Profanen vor dem Magischen und Sakralen. In dieser fazetuösen Antwort erweist sich Fisilinus als dem Doktor intellektuell überlegen, und dafür lässt die Fazetie ihm das letzte Wort.

:35, Die Geschwenck Henrici Bebelij [Anm. 17], fol. D viii ${ }^{\mathrm{v}}$; Bebel, Facetien [Anm. 18], I. 62, S. 27: promptissime.

36 Vgl. allgemein Georg Luck, Vir facetus: A Renaissance ideal, in: Studies in Philology 55 (1958), S. 107-121; Theodor Verweyen, Apophthegma und Scherzrede. Die Geschichte einer einfachen Gattungsform und ihrer Entfaltung im 17. Jahrhundert, Bad Homburg v. d. H. [u. a.] 1970 (Linguistica et Litteraria 5), S. 41-48; Heinz-Günter Schmitz, Physiologie des Scherzes. Bedeutung und Rechtfertigung der Ars locandi im 16. Jahrhundert, Hildesheim, New York 1972 (Deutsche Volksbücher in Faksimiledrucken B 2), bes. S. 64-70; Barner [Anm. 2], S. 104 f. et passim; ders., Überlegungen zur Funktionsgeschichte der Fazetien, in: Haug/ Wachinger [Anm. 1], S. 287-310; ders., [Art.] >Fazeties, in: Reallexikon der deutschen Literaturwissenschaft, Bd. 1 (1997), S. 572-575; Bachorski [Anm. 4], 320 ff.; Dicke [Anm. 2]; sowie unten, Anm. 56.

37 Dazu grundlegend Mary Douglas, Purity and danger. An analysis of concepts of pollution and taboo [1966]. With a new preface by the author, London 2004. 
Ginge sie weiter, würde der Witz der Pointe in den gelehrten Gegenargumenten des Doktors ${ }^{38}$ zunichte werden müssen. Stattdessen affirmiert ein angehängter Schlusssatz die Selbstbehauptung des homo facetus: wólches [sc. Heiligthumb] doch vil glauben/das es Esel oder Roßbein sey. ${ }^{39}$ Unklar bleibt, ob dies Erzähler- oder Figurenrede ist. Doch impliziert es in jedem Falle: Der Status der Reliquien - die Frage also, ob es um magischen Missbrauch oder zudem auch um die Fälschung von Reliquien geht - ist für das Funktionieren der Fazetie gleichgültig. ${ }^{40}$ Deren Skopus ist nicht die Praxis, sondern die Rede.

Die Fazetie setzt Normbezüge und Ordnungen des sozialen Wissens zwar voraus, doch nur als Material, an dem sich schlagfertig überbietende, souveräne facetudo beweisen kann. ${ }^{41}$ Die Moralisierung des Handelns, wie sie der Doktor in Form der Kritik an der Reliquienpraxis unternimmt, wird in der Antwort des Fisilinus direkt zurückgewiesen. Nicht auf den ethischen Abgleich konkurrierender Normen kommt es an, sondern auf die fazetuöse Abstimmung der Gegenrede auf die Rede. Ob des Fisilinus Praxis Heilswunder bewirkt oder fauler Zauber ist, kann daher offen bleiben. Der Text ist nicht ethisch akzentuiert, sondern ästhetisch, ${ }^{42}$ und dies scheint charakteristisch für das fazetuöse Textmuster zu sein: Stets geht es im Agon seiner Akteure nicht um die Negierung von Sinngehalten oder normativen Ordnungen. Facetudo demonstriert vielmehr, wer stattdessen jene Kommunikationsoptionen, die in der Rede des Gegenübers in Anspruch genommen wurden, negiert und diesen derart zum Schweigen bringt. ${ }^{43}$ Daher nicht Indifferenz gegenüber dem Normativen das Entschei-

38 Diese Argumente würden die semantische Umgebung der Rede des Fisilinus ausbauen und im gleichen Maße den Plausibilitätsrahmen für die in ihr vorgenommenen Kategorienverschiebungen enger begrenzen.

39. Die Geschwenck Henrici Bebelije [Anm. 17], fol. D viii ${ }^{\mathrm{v}}-\mathrm{E} \mathrm{i}^{\mathrm{r}}$; Bebel, Facetien [Anm. 18], 1. 62, S. 27: Quas [sc. reliquias] tamen multi credunt esse equorum aut asinorum ossa. - Dieser Schlusssatz folgt seinerseits der Logik fazetuöser Repliken, indem er zurn anderen Mal die Richtung des Diskurses ändert: Die Frage der Echtheit der Reliquien ist für die Handlungsordnung der Reliquienpraxis wie für die Redeordnung des fazetuösen Dialogs ohne jede Bedeutung gewesen. Auf der grammatischen Ebene zeigt sich diese Desintegriertheit des Nachsatzes darin, dass für das adversative doch (tamen) jeder Gegenhalt fehlt.

4) Auf dem Wege einer Gegenprobe wäre diese These anhand der Frage zu uberprüfen, ob nicht für zeitgenössische Satiren auf oder Polemiken gegen derartige Reliquienpraxen - sie seien konfessionell oder nicht - der Status der Reliquien gerade zu den konstitutiv geklärten Voraussetzungen gehört und deswegen schon am Beginn entsprechender Texte festgestellt werden muss.

$41 \mathrm{Vgl}$. auch Stroszeck [Anm. 2], bes. S. $8: 3 \mathrm{ff}$.

42 Vgl. ebl., S. $14 \mathrm{f}, 26 \mathrm{f}$., $32 \mathrm{ff}$.

4. Vgl. hierzu auch im einschlägigen Buch VI von Boccaccios vecamerons dit: Uberschrift der dritten Geschichte: Monna Nonna de' Pulci con una presta risposta al meno che onesto moteggiare del vescovo di Firenze silenzio impome (Decameron [Anm. 32], S. 518; vgl. den Schluss der Geschichte S. 519f.). 
dende an der Fazetie wäre, sondern dessen Irrelevanz. In der Fazetie wird nicht die Gültigkeit einer Semantik, sondern die momentane Geltung ${ }^{44}$ des mit ihr verbundenen Kommunikationsanspruchs negiert. Und deswegen treten, um auch dies noch hinzuzufügen, logische Inkonsistenzen im Verhältnis von Rede und Gegenrede in der Fazetie nicht als Problem auf, sondern können sie als eine Möglichkeit lizensiert sein, Erwartungen mit komischem Effekt zu durchbrechen.

\section{Polemik: Hans Wilhelm Kirchhof}

Mit dem in Bebels Fazetie verarbeiteten Sujet kann man im 16. Jahrhundert freilich erzählerisch auch ganz anders und in der Weise umgehen, dass die hier beobachtete fazetuöse Pointierung abgebaut und die Relevanz normativer Bezugsordnungen für das erzählte Geschehen und Sprachgeschehen restituiert wird. Dies soll in den folgenden Abschnitten skizziert werden. ${ }^{45}$ Gut fünfzig Jahre nach Bebels $>$ Facetiae und nur wenige Jahre nach deren deutscher Übersetzung erscheint die Geschichte auch in jener bis 1603 auf schließlich sieben Bände anwachsenden Prosaerzählsammlung, die der Kasseler Hofbedienstete und spätere Spangenberger Burggraf Hans Wilhelm Kirchhof unter dem programmatischen $\mathrm{Na}-$ men >Wendunmuth< kompilierte. ${ }^{46}$ Angelegt zunächst ebenfalls als Über-

${ }^{44}$ Zur Theoriegeschichte der Unterscheidung von Gültigkeit und Geltung vgl. bes. Christian Thiel, [Art.] ,Geltung, in: Enzyklopädie Philosophie und Wissenschaftstheorie, hg. v. Jürgen Mittelstraß, Bd. 1, Mannheim [u.a.] 1980, S. 729, und Christoph Lumer, [Art.] ‘Geltung/Gültigkeit «, in: Enzyklopädie Philosophie, hg. v. Hans Jörg Sandkühler, Bd. 1, Hamburg 1999, S. 450-455.

${ }^{45}$ Mit Blick darauf seien hier vorweg noch drei Details in Bebels Text festgehalten, die im Folgenden eine Rolle spielen werden: 1) Die Reliquien des Fisilinus sind echt oder könnten es jedenfalls sein; allein in dem eben zitierten Nachsatz (vgl. Anm. 39) ist die Möglichkeit einer Fälschung als unbestimmte Mutmaßung vieler (multi) ins Spiel gebracht. Sodann ist es 2) keineswegs beliebig, dass die Kritik an der Praxis des Almosensammlers bei Bebel von einem Gelehrten artikuliert wird, also auf einer moralisch-intellektuellen Ebene, nicht zum Beispiel auf einer disziplinarrechtlichen liegt: Das facele dictum gehört eben in den Bereich höfisch oder urban verfeinerter Konversation. Damit hängt schließlich 3) zusammen, dass der gelehrte Einwand gegen sie die Reliquienpraxis keineswegs abbricht: Im Präsens von Fisilinus' Antwort erscheint sie bei Bebel vielmehr als cine fortgesetzte Ïbung.

16 Kirchhof, ,Wendunmuth [Anm. 32]; vgl. auch Hans Wilhelm Kirchhof, Kleine Schriften. Kritische Ausgabe. Mit einer Bibliographie der $>$ Wendunmuth-Drucke, hg. v. Bodo Gotzkowsky, Stuttgart 1981 (Bibliothek des literarischen Vereins in Stuttgart 302), S. 5-19 (»Leben und Werk des Autors"), 245-265 (Bibliographie der ,Wendunmuth-Drucke); Röcke, Aggression und Disziplin [Anm. 1], S. $121 \mathrm{ff}$. - Das im Titel von Kirchhofs Sammlung formulierte Programm (vgl. auch ,Wendunmuth<, Bd. 1, S. 4 [Vorrede]) heißt im Titel einer etwas jüngeren Anthologie Exilium molancholiae (Näheres bei Elfriede Moser-Rath, Lustige Gesellschaft. Schwank und Witz des 17. und 18. Jahrhunderts in kultur- und sozial- 
setzung von Heinrich Bebels $>$ Facetiae $<,{ }^{47}$ aber enorm erweitert durch eine Fülle kurzer Erzählungen unterschiedlichster Art und Herkunft, erzählt das 1563 erschienene erste Buch des /Wendunmuth in seinem zweiten Teil von der geistlichkeit, dem bapst und dem römischen leben. ${ }^{48}$ Unter diesen konfessionspolemisch hochgerüsteten Texten finden sich vier von Bebels Fisilinus-Geschichten als Erzählungen Von einem stationierer, also eben einem Prediger wieder, der mit dem Versprechen magisch-reliquiärer Heilsbewirkung umherzieht und Reichtümer ergaunert.

Den ersten dieser Kurztexte beginnt Kirchhof mit einer Art von Promythion, welches zusammen mit dem die vierte Geschichte abschließenden versifizierten Epimythion den Zusammenhang der Fisilinus-Schwänke betont $^{49}$ und sie zugleich als paradigmatische Kasus einer generellen Regel deutet:

Wie die geuckler und landfarer immer ein neuwe manier auff die ander, iren gesellen darmit vorzúkommen, und die leut umbs gelt zü bringen, erdencken, also auch das römische nater gezicht und seine pasthart haben neben vorhin genüg lesterlichen lugen irer abgötterey auch die alfentzerey mit dem heiligthümb und stationiren ertraumet und auff die bein bracht. Solcher heiligthümbs kremer gottseligkeit köndet ir allein auß nachbeschriebenen zwo oder dreyen schalckheiten ermessen und judiciren. ${ }^{50}$

Unehrliche Leute, ihre Betrügereien, der katholische Klerus und die altkirchliche Heiligenverehrung bilden in diesem im Jahr des tridentinischen Dekrets über die legitime Anbetung und Verehrung der Reliquien publizierten Text eine Isotopienkette, in die auch das stationieren des Fisilinus gehört. Wie in der Täuschung überhaupt manifestiere sich in katholischer Frömmigkeit und ihrer Reliquienpraxis im Besonderen ein erlösungsbedürftiger Weltzustand, sodass aus den Schwänken eine klare Ermahnung zu deduzieren ist:

Wer einem wolff trauwt auff der heid,

Den bauwren glaubt auff iren eyd,

Und einem mönch auff sein gewissen,

Der wirt mit allen dreyen bschissen."

geschichtlichem Kontext, Stuttgart 1984, S. 52-55); vgl. auch Schmitz [Anm. 36], bes. S. $116 \mathrm{ff}$.

47 Kirchhof, , Wendunmuth [Anm. 32], Bd. 1, S. 4 (Vorrede).

48 Ebd., S. 439.

40 Ebd., S. 538 ff., Nr. I 2.75-2.78. Auch die Überschriften (Nr. I 2.75: Von einem stationierer; I 2.76: Von disem noch eine historia, I 2.77: Von demselben, I 2.78: Von demselbigen) zeigen die Serialität der Schwänke und ihre gruppenmäßige Zusammengehörigkeit.

50) Ebd., S. 5.38 (Nr. I 2.75).

5) Ebd., S. 540 ( Nr. I 2.78). Dieses Epimythion bezieht sich auf alle FisilinusSchwänke gemeinsam, wie sich schon daraus ergibt, dass die ersten der Nummern (Nr. I 2.75-2.77) ein solches im ,Wendunmuthe regelhaftes morale rhei- 
Die wilde Natur, das ständisch Inferiore und das konfessionell Andere negieren hiernach verlässliche soziale Ordnung (Vertrauen, Eid) und deren Verankerung in der göttlichen Gnade (Gewissen ${ }^{52}$ ). So etablieren die Rahmenpartien der Gruppe der Fisilinus-Schwänke im sWendunmuth einen fixen, in der konfessionellen Kontroverse abgesicherten Deutungs- und Wertungszusammenhang, ${ }^{53}$ innerhalb dessen das protestantische Urteil über katholische Reliquienpraxis völlig unzweideutig und stabil ist.

Schon dieser Deutungsrahmen ändert grundsätzlich die Semantik der in ihn eingelassenen Schwankerzählung von des Fisilinus Verteidigung seiner Reliquienpraxis. Selbst einer bloß momentanen Irrelevanz normativer Begründungszusammenhänge im Hier und Jetzt des Erzählens ist in diesem Rahmen überhaupt kein Raum gelassen. Auf den rhetorischen, den ästhetischen Reiz eines facete dictum, etwa jenseits konfessioneller Antagonismen, kann es unter den Bedingungen dieses Deutungsrahmens keinesfalls ankommen. Die Ästhetik dessen, was einst die witzige Pointe war, wird gänzlich von einer ethischen Orientierung dominiert, die sich in der Negierung des Anderen als eines Abweichenden konstituiert. So nahe Kirchhofs Übersetzungen bei Bebels Fisilinus-Texten bleiben, so wenig könnte bei ihnen daher, wie bei jenen, von einem fazetuösen Textmuster gesprochen werden.

So nahe auch Kirchhofs Übersetzung beim Wortlaut Heinrich Bebels bleibt, so deutlich schreibt sich doch in wenigen, aber prägnanten Abweichungen dem splot selbst jener konfessionalistische Agon ein, welchen die Rahmenpartien der Schwankgruppe (und darüber hinaus selbstverständlich die gesamte Erzählsammlung) vorgeben. So sind, wie im nachfolgenden Schwank (Nr. I 2.75) geklärt wird, die verstorbne[n] heiligen, deren gebein Fisilinus mit sich fürete (S. 538) und für deren Heilswirkung die Bauern in ihrer Pestangst ihm opfern, in Wahrheit Pferde (S. 539). Es kommt also nicht im Interesse fazetuöser Virtuosität auf den ungeklärten Status der Reliquien, sondern im Gegenteil auf die Eindeutigkeit der Fälschung an: Der aggressiv konfessionelle Deutungsrahmen schließt aus, dass es beim katholischen Klerus etwas geben könne, das nicht manifest betrügerisch wäre. Dies sieht man sodann auch daran, dass Fisilinus die

mens weif (ebd., S. 5) nicht haben. Moralisierende Vereindeutigungen dieser Art gehören im Übrigen zu den charakteristischen Tendenzen der Rezeption fazetuösen Erzählens in den deutschen Prosaerzählsammlungen des 16. Jahrhunderts; vgl. Dicke [Anm. 2], bes. S. 171-176; einen mit dem, Wendunmuth in dieser wie in anderer Hinsicht vergleichbaren Fall beschreibt Hans-Jürgen Bachorski, Ersticktes Lachen. Johann Sommers Fazetiensammlung >Emplastrum Corne-lianum‘, in: Röcke/Neumann [Anm. 4], S. 103-122.

52 Vgl. Heinz D. Kittsteiner, Die Entstehung des modernen Gewissens, Frankfurt/ M. 1995 (st.w 1192).

53 Vgl. auch Röcke, Aggression und Disziplin [Anm. 1], S. $124 \mathrm{f}$. 
Bauern der Heilswirkung der roßbein (S. 539) ausdrücklich versichert unter Berufung auf sein Gewissen und namhafte zeugnuß päbstlicher heiligkeit, deren warheit, wie es sarkastisch heißt, seine wort ehrlicher gemacht hätten (S. 538). Dabei weist nichts darauf hin, dass auch diese Garantien - in denen sich das zuletzt durch das Tridentinum erneut betonte Erfordernis päpstlicher Approbation verehrungswürdiger Reliquien reflektiert $^{54}$ - etwa gefälscht wären. Demnach wird unterstellt, dass der Papst tatsächlich die Pferdeknochen als Reliquien anerkannt habe, ${ }^{55}$ und auch darin würde offenkundig, was zu den ideologischen Voraussetzungen des Textes gehört: Die authentischen päpstlichen Dokumente beglaubigen stets die Lüge.

Am deutlichsten aber verschiebt der letzte Satz, welchen Fisilinus in Kirchhofs Text spricht, den Akzent vom ästhetischen Reiz der fazetuösen Pointe im Konversationszusammenhang mit dem Gelehrten auf das ethische Problem des Betrugs in der Reliquienpraxis des katholischen Klerikers: Wenns hilfft, wenn Krankheit also ausbleibt, so glaubt meinen worten und deß heiligthümbs krafft, wo es fehl schlecht, kan ich mich also verantworten, d.h. darauf verweisen, dass die Bauern allein das glaß [...] und nit das heiligthümb geküsst hätten (S. 539). Nicht Schlagfertigkeit ist hier das Entscheidende, sondem der Zynismus eines offenbar von langer Hand vorbereiteten salvatorischen Arguments, welches den Reliquienkult für die Rezipienten des Textes als intendierten Betrugszusammenhang offenlegt. Dieserart bestätigt sich exemplarisch, was im Allgemeinen längst gewusst und daher der Geschichte vorangestellt wird: dass eben [s]olcher heiligthümbs kremer gottseligkeit (S. 538) in Wahrheit keine sei.

Gattungshistorisch passt Kirchhofs Übersetzung von Bebels Fazetie ins literaturwissenschaftlich etablierte Bild (auch wenn man als Funktionsverschiebung konzipieren könnte, was in diesem Bild als Wertungsgefälle erscheint): Die »Geschichte der deutschsprachigen Rezeption der Fazetie in den Schwanksammlungen [ist] insgesamt die[jenige] hartnäckiger Verzeichnungen und Verfehlungen ihres Skopus als spontan geprägtes Witzwort oder Bonmot«, und das hat nicht zum Geringsten damit zu tun, dass die Texte »an die traditionelle kleinepische Aufgabe normativer Verhaltensorientierung « angepasst werden. ${ }^{56}$ In diesem Sinne ist für Kirchhofs

54 Vgl. oben, S. 447 f., sowie unten, Anm. 68.

55) Jedenfalls wäre dies unter der Voraussetzung konfessioneller Differenz die aggressivere Variante gegenuber der Allernative, dass ein einzelner Kleriker mit den Reliquien auch deren kirchenamtliches Echtheitszeugnis gefälscht hätte.

"t; Dicke [Anm. 2], S. 172. Vgl. auch Renate Bebermeyer, [Art.] ,Fazetiex, in: Enzyklopädie des Märchens, Bd. 4 (1984), Sp. 926-9333, bes. Sp. 930 f.; Barner, İberlegungen zur Funktionsgeschichte der Fazetien [Anm. 36], bes. S. $301 \mathrm{ff}$; Röcke [Anm. 4], S. 96 ff. - Zur gattungssystematischen Bestimmung des Verhältnisses von Fazetie und Schwank gibt es dariber hinaus in der älteren Forschung eine 
Text das >enoncé<, das sind die Täuschungszusammenhänge katholischer Frömmigkeitspraxis, weit wichtiger als die senonciation< der Antwort des Fisilinus. Weniger Gelächter oder fazetuöses Vergnügen könnte daher eine Antwort auf den Text sein, als viel eher die Ausdrucksformen einer sei es empörten, sei es verständnislosen Distanzierung des Anderen und zugleich einer irritationsfreien Vergewisserung der eigenen Orientierungskomplexe. Insofern geht es in Kirchhofs Text um die narrative Reproduktion eines vorgegebenen Wertungszusammenhangs durch Dramatisierung normativer Differenzen, und das Textmuster solcher Reproduktion ist nicht das Fazetuöse, sondern das Exemplarische. ${ }^{57}$ Dieser Wertungszusammenhang darf daher weder momentan irrelevant sein - wie in der Fazetie noch problematisch. Er muss vielmehr als das fraglos Selbstverständliche zur Geltung gebracht werden, und er wird es hier.

Dieses Selbstverständliche aber ist bei Kirchhof in einem konfessionellen Schema geordnet, das asymmetrische Gegenbegriffe nicht aufhebt, sondern auf ihnen basiert und sie zugleich stabilisiert: Das gesamte semantische System des vorliegenden Textes ist vom axiologischen Gefälle zwischen >Ehrlichkeit $\times$ und $>$ Gelehrsamkeit< auf der Seite des Kritikers (einem ehrliche $[n]$ gelehrte $[n]$ mann [S. 538]) als der einzig positiven Instanz des Textes und andererseits dem römische[n] nater gezicht (ebd.) her organisiert. Und dies sind asymmetrische Kategorien, insofern sie den einen Term (>Natterngezücht ) als partikularen Gegenbegriff, den anderen aber (-Ehrlichkeit ), der die eigene Normposition bezeichnet, als alternativenlosen Universalbegriff konzipieren. Partikulares weiß sich so als das universal Gültige. Es kann alles Andere als Abweichendes negieren, als eine Nichtigkeit, welche die zweifelsfreie Geltung des Gültigen nicht berührt. Und insofern liegt ein geschlossenes konfessionalistisches Normund Deutungssystem vor. Was Heilswunder, was fauler Zauber sei, ist in ihm stets vorab entschieden, und der Gebrauch ironischer Redeformen ${ }^{58}$ zeigt überdies an, dass sich der Text seiner normativen Basis als Rahmen eines mit den Lesern geteilten Vorverständigtseins sicher sein kann.

Von religiöser Pluralisierung könnte angesichts eines solchen literarischen Diskurses allenfalls in einem höchst vagen Sinne gesprochen werden. Kontingenzerfahrungen, Irritationen, das Versagen etablierter Kategorisierungen der Weltauslegung, das Problematischwerden von Negierbar-

ganze Reihe heute unmethodisch wirkender Vorstöße von allenfalls noch forschungsgeschichtlichem Interesse; vgl. etwa Wilhelm-Klaus Nawrath, Facetie und Schwank - ein Vergleich, in: Möckelmann [Anm. 17], S. 115-129.

57 Anders etwa Schmitz [Anm. 36], S. 33ff. - Stroszeck [Anm. 2], S. 32 ff., hat in diesem Zusammenhang von sauratischer Integration gesprochen.

Lum Beispiel: heiligthümbs kremer gottseligkeit (S. 538), verstorbner hoiligen (wie hernach wolgt) (ebd.). 
keiten, die mit dem Pluralisierungsbegriff verbunden werden sollten, sind hier in der Dramatisierung konfessioneller Differenz gerade ausgeschlossen.

\section{Pluralisierung: Jakob Frey}

Die dritte Version der Geschichte vom Reliquienmissbrauch, die ich hier diskutieren will, erzählt sie nicht von Fisilinus, sondern von einem namenlosen, völlig verarmten pfaff auff dem Odtenwald (S. 49, Z. 6) ${ }^{59}$ Diese Version steht in der 1557 in Straßburg erschienenen >Gartengesellschaft<, einer von Jakob Frey, Stadtschreiber im elsässischen Maursmünster, zusammengestellten Sammlung von Prosaschwänken. Hier gerät die fazetuöse Pointe nicht a priori unter konfessionalistische Deutungsvorgaben. Wohl aber wird sie unter veränderten narrativen Bedingungen umfunktionalisiert. Das Erzählte ist nämlich durch Anonymisierung aus der Serialität der Fisilinus-Geschichten herausgelöst und zugleich durch Lokalisierung [i]m Würtzburger bistumb (S. 49, Z. 5) als singulärer Vorgang mit Authentizitätsanspruch ausgestattet. Dabei tritt an die Stelle der semantischen Konstitutionszusammenhänge der jokos pointierten Konversation (Bebel) beziehungsweise der konfessionalistischen Polemik (Kirchhof) ein ökonomischer und kirchenrechtlicher Nexus. Er wird in einer Erweiterung des ErzähIsyntagmas aufgebaut, das nicht lediglich »Aufschwellung statt Pointierung ${ }^{60}{ }^{\circ}$ bietet, sondern die Prinzipien der Fazetie durch eine andere narrative Logik substituiert: Die zweiteilige Episodenstruktur der Vergleichstexte (1. >Aktion<: Almosensammeln bei den Bauern, 2. ^Dialog: Auseinandersetzung mit dem Kritiker) ist in der Fassung der >Gartengesellschaft ‘durch eine thematisch zentrierte Erzählklammer zusammengeschlossen. In ihr geht es um die drückende Armut des Pfaffen und um deren Überwindung: Ein gar kleines pfründlin innehabend, darauff er sich [...] nit wol emeeren mocht (S. 49, Z. 7f.), aber auch nicht gelert oder geschickt genug, als das man im ein andere, ertragreichere pfarr vertrawen dorffte (S. 49, Z. 9 f.), macht der Pfaffe sich mit einer gefälsch ten Reliquie zum Almosensammeln auf, um dem Bettel zu entgehen (S. 49, Z. 10f.). Demgemäß wird nicht ein gelehrter Doktor sein Kritiker, sondern der official (S. 49, Z. 23) des Bistums. Am Ende kehrt der Pfarrer in die Legalität zurück, indem er, dieserart auch faktisch auf eine Fortsetzung

59. Frey, Gartengesellschaft [Anm. 32], S. 49f, cap. 34. Vgl. zu dieser Erzählsammlung Röcke, Aggression und Disziplin [Anm. 1], \$. 110 ff.; zu ihren Bearbeit.ungstendenzen Kipf [Anm. 17], S. 238-242; zum Autor: Elfriede Moser-Rath, [Art.] ,Frey, Jacob<, in: Enzyklopärlie des Märchens, Bd. 5 (1987), Sp. 3333-341.

(5) Dicke [Anm, 2], \$. 172. 
seines Betruges verzichtend, die falsche Reliquie aus der Monstranz entfernt und wegwirft: Er braucht sie nicht mehr, denn er hette sich bey dem aploß wol gewermbt (S. 50, Z. 6f.).

So aber wird die Erzählung in dem von Jurij M. Lotman explizierten Sinne sujethaft. Es gibt einen Zweck, der sich als »Kampf mit der Konstruktion der Welt« versteht, ${ }^{61}$ nämlich die Bekämpfung der Armut. Und Mittel zu diesem Zweck ist, was narrativ in die Mitte zwischen den Anfang der Erzählung bei der Armut des Pfaffen und deren Ende bei seiner Wohlhabenheit gesetzt ist: der Reliquienbetrug und dessen Verteidigung gegenüber dem bischöflichen Amtsträger. So ist die Erzählung teleologisch geschlossen. Die anfängliche Kontingenz der epischen Welt kann (für die Dauer der Erzählung) endgültig bewältigt werden. ${ }^{62}$

Darin steckt freilich weder die Pointe von Jakob Freys kurzer Erzählung noch das systematische Problem, das sie zur Analyse aufgibt. Pointe und Problem liegen vielmehr in jener zweiten Binnenepisode, in welcher der Priester durch den Würzburger Official abgemahnt wird, sich verteidigt und Gehorsam verspricht. Der Bistumsbeamte zeigt im an, das solche und dergleichen ding abgöttisch werend, fürten das einfeltig volck inn ein falschen glauben (S. 49, Z. 24-26), während der Pfarrer wie bekannt antwortet: Sein Heilsversprechen sei wahr, die Bauern hätten lediglich die Monstranz berührt, und ehe er sie sein heilthumb liesse küssen (S. 50, Z. 2), wolle er sie übrigens dem Teufel überantworten. Den Abschluss bildet ein schwanktypischer Absturz ins Anal-Skatologische: Wann sie mich im hindern viertheil küssen wolten, ich wolt inen nit heben (S. 50, Z. 2 f.). ${ }^{63}$

Bis in den Wortlaut hinein ist die Konfrontation von Pfarrer und Vorgesetztem aus der fazetuösen Konversation entwickelt. Und auch die Pointe

(1) Jurij M. Lotman, Zur Metasprache typologischer Kultur-Beschreibungen, in: ders., Aufsätze zur Theorie und Methodologie der Literatur und Kultur, hg. v. Karl Eimermacher, Kronberg/Ts. 1974 (Forschungen Literaturwissenschaft 1), S. 338-377, hier S. 359; vgl. auch oben, Anm. 3.

62 Vgl. Rainer Warning, Die narrative Lust an der List: Norm und Transgression im iTristan<, in: ders., Gerhard Neumann (Hgg.), Transgressionen. Literatur als Ethnographie, Freiburg/Br. 2003 (Rombach Wissenschaften, Reihe Litterae 98), S. $175-212$, bes. S. $179-184$.

(6) Ein Witz von Freys Geschichte beruht also auf einer semantischen Ambiguität: heillumb ist in der Begegnung mit den Bauern der insgesamt heilsvermittelnde Zusammenhalt von Monstranz und Reliquie (Gartengesellschaft [Anm. 32], S. 49, Z. $16 \mathrm{f}$.), im Gespräch mit dem vorgesetzten Official hingegen ist heiltumb gerade nur die Reliquie, und zwar im kategorialen Unterschied zum Reliquiar (S. 49 . Z. 32 f.; S. 50, 7. 2): Hier bezeichnet der Ausdruck also etwas sakral Unberührbares, und das setzt in der Fügung mit dem Possessivpronomen und dem Kuss (mein heillhumb [...] küssen [S. 50, Z. 2]) überdies Assoziationen ans Anale frei: im hindern vientheil küssen (S. 50, Z. 3). 
der Fazetie ist erhalten. Dennoch funktioniert der Dialog bei Frey in ganz anderer Weise, denn die Äußerungen der Antagonisten geraten in andere Kontexte als bei Bebel und Kirchhof und unter andere Voraussetzungen. Einerseits instrumentalisiert der Protestant Frey den Schwank nicht im Rahmen konfessioneller Polemik: Bei ihm ist - was beim Protestanten Kirchhof undenkbar wäre - gerade die katholische Obrigkeit jene Instanz der Wahrheit, die Reliquienbetrug straft und unterbindet. Andererseits und im Gegensatz zu Bebels Text ist hier nicht die fazetuöse senonciation<, die ästhetische Seite des Wortwechsels gegenüber seinem ethischen Gehalt privilegiert. Normativität ist nicht bloß Material schlagfertiger Selbstbehauptung, sondern gewinnt hier als solche Relevanz. Denn statt der Konversation zweier kultivierter Gesprächspartner liegt ein kirchenrechtliches Sanktionsverfahren vor: Der Official mahnt den Priester ab und droht im Weigerungsfalle mit übergeordneten Instanzen und weiterreichenden Konsequenzen: Der Pfarrer solte von dem schantlichen wesen abstehn, oder er, der official, würde dise handlung für den bischoff vonn Würtzburg selbs bringenn müssen (S. 49, Z. 26-28). Die sozusagen horizontale Selbstbezüglichkeit des Dialogs, seine Pointenstruktur, ist also zwar gewahrt, sie wird aber dominiert von der, wie sich formulieren ließe, vertikalen Referenz auf den Kasus des Reliquienbetrugs selbst. Dieser Kasus gibt nicht lediglich Anlass und Material der Konversation, sondern er ist der Gegenstand des Dialogs und mit diesem handlungslogisch verknüpft. Weil der Pfaffe bei seinem Vorgesetzten denunziert wird (S. 49, Z. 23), kommt es überhaupt zum Dienstgespräch, und anders als in den Vergleichstexten zeitigt dieses auch konkrete Folgen: Der Pfaffe hört mit dem Reliquienbetrug auf. ${ }^{64}$

Freilich: so konventionsgerecht geglättet, wie es bisher den Anschein haben mag, ist Freys Schwankerzählung keineswegs. Der Wegfall konfessionalistischer Deutungsvorgaben, die sujethafte Erweiterung des Erzählkerns, die Transposition des Dissenses von Protagonist und Kritiker aus dem Sonderraum fazetuöser Konversation ${ }^{65}$ in den Rahmen kirchenamtli-

64 Deswegen ließe sich die Abfolge von Reliquienbetrug und Dialog mit dem Vorgesetzten auch als Realisierung eines schwanktypischen Wiederholungsmusters interpretieren: Der Schwankheld muss den in der ersten Episode ergaunerten Gewinn neuerlicher Gefährdung aussetzen, um ihn in listiger Selbstbehauptung dann endgültig zu sichern.

(4) Für ihn steht in der Tradition der Renaissance-Fazetien jenes an abgelegenem Ort des Papstpalasts situierte Bugiale der Kuriensekretäre, das Poggio im Schlusswort seines , Liber facetiarum (Poggio Bracciolini, Facezie, hg. v. Stefano Pittaluga, Mailand 1995 (1 grandi libri Garkanti 570), S. 296) als Ausnahmeort einer die hierarchischen und moralischen Ordnungen seiner Imwelt ignorierenden Obszönität und Scharfzüngigkeit preist. Vg]. dazu auch Barner [Anm. 2], S. 102f., 105ff; ders., Überlegungen zur Funktionsgeschichte der Fazetien [Anm, :36], S. 294, 299f.; Bachorski [Anm. 4], \$. 328ff. 
cher Institutionalität samt handlungslogischer Verkoppelung von Reliquienbetrugs- und Dialogteil des Schwanks: all dies produziert eine Reihe irritierender Unabgestimmtheiten.

Das zeigt sich zunächst an der Anschuldigung des Officials, das Treiben des Pfarrers führe das einfeltig volck inn ein falschen glauben (S. 49, Z. 25 f.), denn es sei abgöttisch (S. 49, Z. 25). Anders als im fazetuösen Dialog oder in der konfessionellen Polemik ist dies im Rahmen eines innerkatholischen Dienstgesprächs ein kirchenrechtlich relevanter Ausdruck. Er kann sich nach Lage der Dinge allein auf das Versprechen des Pfaffen beziehen, die Berührung des heilthumb garantiere Seuchenschutz. Eine solche Behauptung sistiert nämlich zwar nicht das Transzendenzmoment, wohl aber das Gnadenmoment reliquiärer Heilswirkung, ihre gnadenhafte Unverfügbarkeit. Transzendenz aber, die verfügbar wäre, ist logisch aporetisch und theologisch heterodox: nicht Heilswunder, sondern fauler Zauber. Und das Almosensammeln mit Hilfe eines solchen superstitiösen Versprechens ist daher, wie das Tridentinum fünf Jahre nach Freys ,Gartengesellschaft< erneut dekretieren wird, als turpis quaestus verboten. ${ }^{66}$ Mithin ist es magischer Missbrauch, den der Official abmahnt, nicht aber die Fälschung einer Reliquie - hier des heiligen Rochus ${ }^{67}$ - unter Verwendung eines Eselsknochens. Von jener Fälschung hat der Kirchenobere gar keine Ahnung, obwohl er sie haben müsste. ${ }^{68}$ Seine Anklage unterstellt vielmehr die Echtheit der Reliquie, und diese Unterstellung wird noch nachträglich bestätigt, wenn der Pfaffe sich mit den Worten verteidigt, er habe die Bauern das heilthumb (S. 49, Z. 32 f.) in keinem Fall berühren lassen. Hingegen der Skopus jener vorangegangen Episode ist gerade die Fälschung der Reliquie gewesen. Verwerfliche Tat dort und Schuldvorwurf hier stehen unabgestimmt nebeneinander.

"Omnis porro superstitio in Sanctorum invocatione, reliquiarum veneratione et imaginum sacro usu tollatur, omnis turpis quaestus eliminetur [...] (Denzinger, Enchiridion symbolorum (Anm. 25], Nr. 1825). Vgl. zu den Versuchen der Kirche, die Praxis dos Almosensammelns unter Kontrolle zu bekommen, auch Nikolaus Paulus, Geschichte des Ablasses im Mittelalter. Vom Ursprunge bis zur Mit.le des 14. Jahrhunderts, 2. Aufl, Bd. 2, Darmstadt 2000, S. 206-227.

it Vgl. zu Rochus Irene Vaslef, The role of St. Roch as a plague saint: A late medieval hagiographic tradition, Diss. Washington, Catholic University of America 1984 (darin zu seinen Reliquien S. 146-149); F[rancesco] Scorza Barcellona, [Art.] >Rochus<, in: Lexikon des Mittelalters, Bd. 7 (1999), Sp. 926.

fis Eigentlich müsste der Official Verdacht schöpfen, weil seit dem 13. Jahrhundert die Verehrung neu gefundener Reliquien eine Erlaubnis des römischen Bischofs voraussetzt, (Denzinger, Enchiridion symbolorum< [Anm. 25], Nr. 818): Im bischöflichen Ordinariat in Würzburg müsste demnach bekannt sein, dass auff dem Odtemald bey Halmum (S. 49, Z. 6) und im Besitz dieses Pfarrers keine Reliquie des heiligen Rochus existieren kann. 
Nicht weniger sperrig verhält sich sodann gegenüber dieser Anschuldigung auch die Verteidigung des Pfaffen:

Ich hab den bauren recht gesagt, welcher das heilthumb küsse, der sey diß jar vor der pestilentz sicher. Es haben auch die bauren nur das glaß geleckt unnd geküßt, und nit das heilthumb. (S. 49, Z. 30-S. 50, Z. 1)

Im Rahmen fazetuöser Konversation ist das schlagfertige, erwartungsdurchbrechende Abweichen von den diskursiven Vorgaben des Gegenübers die Produktionsweise witziger Pointen. Hingegen müsste man im Blick auf die ganz anderen Konsistenzstandards juristischer Kommunikation sagen, dass der Official und sein Untergebener aneinander vorbei reden. Nicht, dass die Bauem das Heiligste berührten und durch ihre Berührung möglicherweise entheiligten, war gerügt worden, sondern dass ihnen im Gegenzug für ein angemessenes Almosen mit solcher Berührung magischer Krankheitsschutz zugesichert worden war.

Und so geht es weiter. Zum Mangel an Passgenauigkeit zwischen Fälschungshandlung, Missbrauchsvorwurf und Verteidigung kommen weitere Ungereimtheiten hinzu. Der Anklage abgöttisch [en] Tuns (S. 49, Z. 25) folgen keineswegs Prozess oder Bestrafung; das Almosensammeln wird als superstitiös gebrandmarkt, doch fehlt die zwingende Konsequenz, dass die ergaunerten Güter dann eingezogen werden müssten; der Pfaffe weist die Anklage des Vorgesetzten zurück, nur um im selben Atemzug ihm doch auch Recht zu geben und sich ihm zu unterwerfen: Aber euch, herr official, wil ich volgen; ich hab die Bauern uff daß mal gnüg beschissen (S. 50, Z. 4 f.). Wer wollte hier noch zwischen Indolenz und Oboedienz unterscheiden? Und übrigens war der Betrug an den Bauem ursprünglich nicht schwankhafter Selbstzweck gewesen, sondern bloß das Mittel zur Bekämpfung der eigenen Armut.

Entscheidend ist hierbei, dass solche Uneindeutigkeiten von der Erzählung nicht aufgelöst, sondern vielmehr in unverdeckter Kontingenz offen gelassen werden. Die Relevanz des Normativen wird mit der Situierung des Konflikts im klerikalen, kirchenrechtlichen Diskursraum explizit eingeführt, und gleichzeitig schwinden Kongruenzen und Unterscheidungen, auf welchen die Ordnung dieses Diskursraums allererst beruht. Einerseits verhalten sich Amt und Wissen kontingent zueinander: Der Pfaffe ist dem Official in der Hierarchie des hier relevanten Wissens übergeordnet (deswegen kann er ihm erfolgreich widersprechen), in der Hierarchie der kirchlichen Ämter aber untergeordnet (deswegen gehorcht er ihm) ${ }^{69}$ An-

69 Amt und Wissen sind zudem insoferm bloß lose gekoppelt, als das Amt auch über falsches Wissen verfügen kann, ohne dass dies als solches thematisiert. wäre: Der (official hält die Reliquie für echt (vgl. dazu Anm. 68), während der 
dererseits verfällt die fundamentale Unterscheidung von Normativität und Normbruch: Wenn man zugleich widerständig und gehorsam, zugleich schuldig wie unschuldig sein, wenn man zugleich schuldig sein und doch straffrei bleiben kann und wenn man illegitim erworbenen Besitz behalten und genießen darf, dann geschieht anderes und mehr, als dass irgendeiner Norm ihr Bruch gegenübergestellt würde. Dann löst sich vielmehr die für die erzählte (wie für jede) Ordnung konstitutive Opposition von Normativität und Übertretung, ${ }^{70}$ von Gesetz und Verbrechen selbst auf. Das Sinnzentrum dieser Ordnung wird nicht für die Dauer einer fazetuösen Pointe eingeklammert, sondern es erodiert. In den Uneindeutigkeiten und offenen Unabgestimmtheiten bleibt es am Ende der Erzählung destruiert zurück, ${ }^{71}$ und zwar ohne dass dies für die Schwankerzählung und ihren Witz eigentlich erforderlich wäre.

In Jakob Freys simpler Schwankerzählung wird Kontingenz in einer Weise freigesetzt, in der man wohl so etwas wie die Spur eines Verfalls "geschichtliche[n] Sinnvertrauen[s] «" ${ }^{72}$ sehen darf. Die Geschichte tritt aus der oppositiven Ordnung von Affirmation und Negativierung heraus, ohne dass diese doch, wie in Bebels Fazetie, zugunsten des Witzes einfach irrelevant gemacht wäre. Weder geht es hier um eine Positivierung von Reliquienbetrug oder -missbrauch, noch lässt sich die Geschichte, wie bei Kirchhof, als konfessionelle Negativierung katholischen Reliquienkults entschärfen. Weder geht es um eine Vernichtung kirchlicher Autoritätsansprüche noch um deren Stärkung. Was erzählt wird, wäre in den Schematismen asymmetrischer Gegenbegriffe von >gut< und >böse<, >sakrak und profan nicht mehr zu deuten. Die alternativen Terme treten vielmehr in kontingenten Kontiguitäten zueinander und verlieren ihre Negierbarkeit. ${ }^{73}$ Eben für solche Konstellationen sollte der Ausdruck >Pluralisierung< vorgesehen sein.

Pfaffe wie der Erzähler und die Rezipienten der Geschichte wissen, dass sie gefälscht ist.

${ }^{70}$ Vgl. Warning [Anm. 62], S. 185 ff.

${ }^{71}$ Mit Lotmans narrativer Semiotik (vgl. Anm. 3 und 61) könnte man sagen, was der Text als epische Welt (des Klerus) entwerfe, sei insofern kein »Kulturmodell« mehr, als diesem Entwurf das Entscheidende fehle: »Orientiertheit«; vgl. Warning [Anm. 62], S. 190.

${ }^{72}$ Ebd., S. 18:3; vgl. Rainer Warning, Erzählen im Paradigma. Kontingenzbewältigung und Kontingenzexposition, in: Romanistisches Jahrbuch 52 (2001), S. 176 209, hier S. 180.

7:3 Daraus ergibt sich übrigens, dass auch eine Interpretation, die hier im Interpretationsrahmen von Karnevalisierung und Lachkultur (vgl. oben Anm. 1) etwa die (sagen wir: von dem armen Pfaffen verkörperte) plebejische Subversion gegebener Autoritaten sähe, solche Spuren epistemischer Verunsicherungen verwischen würde. Sic müsste - vorbei an seinen Uneindeutigkeiten - Eindeutigkeit des Textes herstellen, wo die Terme der Erzählung unabgestimmt, ihre Relationen ambig sind. Vgl. auch Röcke, Aggression und Disziplin [Anm. 1], S. $110 \mathrm{ff}$. 


\section{Exkurs: Christusträger}

Die Problemkonfigurationen, die sich in der hier verfolgten Textreihe abzeichneten, können für die narrativen Repräsentationsformen religiöser Praxis in den Fazetien und Schwankerzählungen des 16. Jahrhunderts keineswegs Repräsentativität beanspruchen. Wohl aber sind sie signifikant in dem Sinne, dass sie den Möglichkeitsraum solcher Formen markieren. Und daher sind diese Problemkonfigurationen auch nicht singulär. Wie sie hier von einer Reliquienbetrugsgeschichte her entwickelt wurden, ganz ähnlich hätten sie sich daran zeigen lassen, wie ein Witz über den paränetischen Gebrauch der Christophorus-Legende die frühmoderne Fazetienund Schwankliteratur durchquert. ${ }^{74}$ Ich deute das nur mit ganz wenigen Strichen an:

In der in gewissem Sinne gattungsbegründenden Sammlung Poggio Bracciolinis ${ }^{75}$ wird von einem facetus quidam erzählt. Er beantwortet die unablässig wiederholte rhetorische Frage eines schlechten Predigers, wem denn je größere Gnade widerfahren sei als dem heiligen Christusträger, mit einem Zwischenruf: Weit mehr Gnade als Christophorus sei jenem Esel zuteil geworden, der, auf der Flucht nach Ägypten, nicht allein Christus, sondern zudem auch dessen Mutter getragen habe. ${ }^{76}$ Schon die Antwort als solche macht die kommunikative Strategie der Predigerfrage zunichte, die als rhetorische auf eine Antwort gerade nicht angelegt war. ${ }^{77}$ Zugleich über- und unterbietet der Inhalt der Antwort die in der rhetorischen Frage gegebene Proposition und destruiert sie damit: Er unterstellt, der Prediger fasse Gnade als etwas Quantifizierbares auf, und setzt dem Christophorus den eindeutig tiefer rangierenden Esel sowie dem einzelnen Jesus sodann Sohn und Mutter gemeinsam entgegen.

Dieser Modellfall einer fazetuösen, den kommunikativen Raum witzig dominierenden Äußerung wird im zweiten Band von Hans Wilhelm Kirchhofs >Wendunmuth $\times$ konfessionalistisch negativiert: Die Christophorus-

${ }^{74}$ Die Beispielreihe und die Grundzüge der Interpretation verdanke ich Michael Waltenberger.

75. Poggio, Facezie [Anm. 65]; dazu insbesondere Barner [Anm. 2], S. $101 \mathrm{ff}$; vgl. auch Lionello Sozzi, Le $>$ Facezie e la loro fortuna europea, in: Poggio Bracciolini 1380-1980. Nel VI centenario della nascita, Florenz 1982 (Studi e testi 8), S. 235-259; Armando Bisanti, Alcune osservazioni sulle >Facezies di Poggio Bracciolini, in: Schede medievali 10 (1986), S. 66-86; Stefano Pittaluga, Poggio fra Cicerone ed exemplac, in: Res Publica Litterarum 10 (1987), S. 267-274; Barner, Überlegungen zur Funktionsgeschichte der Fazetien [Anm. 36]; Mühlherr [Anm. 16].

76: Poggio, Facezie [Anm. 65], S. 216, Nr. 200.

77 Vgl. Heinrich Lausberg, Handbuch der literarischen Rhetorik. Eine Grundlegung der Literaturwissenschaft, 3. Aufl., Stuttgart 1990, \& 767; Harald Weinrich, Textgrammatik der deutschen Sprache, Mannheim [u.a.] 199:3, S. $892 \mathrm{f}$. 
Predigt ist hier Propaganda für den apotropäischen Gebrauch von Heiligenbildchen und aus dem homo facetus wird ein unnützer unhöfflicher wäscher, ${ }^{78}$ dessen Aberglaube sich darin manifestiert, dass er Heiligkeit für messbar hält. Was in Poggios Text schlichte Rhetorik (beim Prediger) und funkelnde facetudo (bei seinem Zuhörer) war, wird in der Erzählsammlung des Lutheraners Kirchhof so zum Exempel einer insgesamt superstitiösen Frömmigkeitspraxis, die bloß noch zeigt, wie man in vorzeiten, also in der katholischen Vergangenheit, ${ }^{79}$ mit unnötigen ungeschickten predigten auch ungeschickte zuhörer hab verursacht (S. 149). Indes: erzählt werden kann das anscheinend nur, wenn zugleich der demgegenüber korrekte normative Rahmen auch in der Erzählsammlung selbst fixiert ist. Deswegen versichert der Erzähler, anders als deren (katholischer) >plot< drücke seine (protestantische) Erzählung keineswegs eine Verachtung Christi oder seiner Mutter aus; deswegen gibt das nachfolgende Stück (S. 149 ff., Nr. II 100) eine protestantisch unanstößige allegorische Auslegung der Christophorus-Legende; deswegen endet diese mit einem gereimten Gebet, zu dessen Abschluss sich der namentlich genannte Autor selbst als Vorsprecher der frommen Gemeinde in Szene setzt (S. 151). Zum andern Male wäre hier also zu beobachten, wie eine allein auf die pointierte Replik zielende und darum die Relevanz des Moralischen, Normativen, Theologischen vorübergehend einklammernde Fazetien-Konstellation bei Kirchhof einer konfessionalistisch disziplinierenden Ausarbeitung unterzogen wird. Und wiederum wäre deutlich, dass solche im Dienste protestantischer Polemik stehende Exemplarisierung der ehemals fazetuösen Konstellation etwas ganz anderes ist als jene Krisen etablierter Deutungsschemata, bei welchen hier von Pluralisierung gesprochen werden sollte. Und wie im Falle der Reliquienbetrugsgeschichten könnte die Textreihe auch hier weiter zu Jakob Freys >Gartengesellschaft ‘ verlängert werden.

Dort gibt es die Christophorus-Predigt ebenfalls. Ihr religiöser Praxiszusammenhang ist dabei nicht die Propagierung des Bilderkults, sondern Reliquiengebrauch. ${ }^{80}$ Der Dialogkern der Geschichte ist hier wiederum syntagmatisch erweitert, indem die Predigt einem mit Berührungsreliquien des heiligen Christophorus umherziehenden questionirer (S. 95, Z. 28

78 Kirchhof, ,Wendunmuth [Anm. 32], Bd. 2, S. 148f., Nr. II 99, hier S. 149.

79. In Kirchhofs Formulierung liegt ein Musterbeispiel für jene »Temporalisierung der Gegenbegriffe « vor, auf welche Koselleck weine Dynamik der Negation des jeweils anderen« zurückführte, "wie sie die nichtchristliche Antike kaum gekannt hat (Koselleck [Anm. 7], S. 70, vgl. ebd., S. $81 \mathrm{ff.}$.).

80) Frey, Gartengesellschaft [Anm. 32], S. 95f., Nr. 81. - Beides, Bilderkult und Reliquiengebrauch, wird übrigens auch im Rechtfertigungsdekret des Tridentinum (vgl. oben, Anm. 30) gemeinsam behandelt, beidem liegt die nämliche präsentistische Funktionslogik (vgl. (iumbrecht [Anm. 24]) zugrunde. 
u. ö.) in den Mund gelegt wird. Sein Lob der Heiligkeit des Christusträgers zielt direkt auf eigenen ökonomischen Vorteil. Der Einwurf eines speyfogel (S. 96, Z. 14), der Esel auf der Flucht nach Ägypten habe mit Mutter und Sohn nicht bloß quantitativ mehr, sondern auch zeitlich länger Gnade getragen als Christophorus, stört diese wirtschaftlichen Interessen. Der questionirer sieht sich ertappt, macht [...] das ampt aus (S. 96, Z. 29) und zieht mit seinem zerrißnen heiligthumb in ein ander dorff (S.96, Z. 31 f.). Diese Expansion der Handlung konstituiert für die Pointe andere Relevanzen als die jenes ästhetischen Reizes, der in ihrer Raffinesse liegt. Doch bleibt in der Schwebe, ob es sich um Relevanzen des religiösen oder solche des ökonomischen Diskurses handelt. So entstehen irritierende Ambivalenzen: Führt die Übertragung der präsentistischen Reliquienlogik auf einen Esel die Behauptungen des Predigers theologisch ad absurdum? Wird umgekehrt deren Geltung gerade vorausgesetzt, um im Rahmen einer Ökonomie der Heilsgüter ein offenbar minderwertiges Reliquienangebot abzulehnen? Ist das eine vom anderen überhaupt zu trennen, sind hier religiöser und ökonomischer Diskurs geschieden oder ungeschieden? Diese Fragen scheinen unbeantwortbar zu sein, und das heißt: Weder ist in der Version Jakob Freys die Relevanz normativer Bezugsordnungen, wie es gattungsgemäß in Poggios Fazetie der Fall ist, momentan suspendiert, noch sind diese Deutungsvorgaben, wie es eine konfessionspolemische Exemplarik voraussetzen würde, eindeutig und stabil.

\section{Schluss: Schwank und Schwankserie}

Diese zweite Beispielreihe zu Fassungen der Geschichte von der Christophorus-Predigt wäre näher auszuarbeiten. Hier sollte sie lediglich illustrieren, dass es die vorangegangenen Kapitel bei jenen Problemkonfigurationen, die sich ihnen an den Versionen der Fisilinus-Erzählung zeigten, nicht mit Ausnahmefällen zu tun hatten. Diese Problemkonstellationen stellten sich so dar, dass ein ’plot‘, für dessen fazetuöse Fassung die Relevanz normativer Bezugsordnungen gänzlich eingeklammert werden kann (`Pointierung`), in den erzählerischen Erweiterungen stoffgleicher Schwänke in unterschiedlicher Weise normativ bezogen wird. Dieser normative Bezug kann, so im Rahmen von Kirchhofs konfessionalistischem Diskurs, durchaus unzweideutig und in exemplarischen Regel-Fall-Subsumptionen fixiert sein (>Polemik ). Er kann sich aber auch als Geflecht unabgestimmter oder widerstreitender Propositionen darstellen, in welchem tatsächlich in distinktem Sinne so etwas wie Pluralisierung greifbar wird.

Diese systematischen Altemativen ließen sich übrigens auch mit den strukturellen ssettings $>$ der Fisilinus-Texte in ihren jeweiligen narrativen Um- 
gebungen korrelieren. Wie in Bebels `Facetiae und deren frühneuhochdeutscher Übersetzung begegnet die Reliquienbetrugsgeschichte, die hier interessierte, auch im >Wendunmuth $<$ und in der $>$ Gartengesellschaft $<$ im Rahmen umfangreicher Erzählsammlungen. Dabei ändert sich freilich ein entscheidendes Detail; ich habe es bereits beiläufig angedeutet. Bei Bebel wie Kirchhof ist die Geschichte jeweils Teil einer seriellen Wiederholungsstruktur: Der Reliquienbetrug gehört dort wie hier in eine als solche deutlich gekennzeichnete Gruppe von Fisilinus-Texten, ${ }^{81}$ und in dieser Gleichförmigkeit der Serie tritt jeweils eine gemeinsame Matrix hervor, die sich in jedem einzelnen Text der Serie erneut manifestiert: Bei Bebel ist dieses Gemeinsame der Typus des homo facetus, der in immer neuen Situationen seine spontane Schlagfertigkeit beweist. ${ }^{82}$ Bei Kirchhof ist das Gemeinsame der Abfolge auch der Fisilinus-Schwänke ${ }^{83}$ der konfessionspolemische Diskurs. Der Funktionsmechanismus der Texte dieser Serie ist gerade nicht, wie in Bebels Fazetienreihe, das Überraschungsmoment der Pointe, sondern die kasuistisch stets wiederholte Bestätigung des vorab längst allgemein Gewussten. Es handelt sich um den Funktionstypus der Exemplarisierung, und er setzt stabile normative Orientierheit und verlässliche Muster der Weltauslegung voraus, ${ }^{84}$ die hier im System konfessioneller Differenzen garantiert sind.

Hingegen Jakob Freys Text ist aus solcher Serialität herausgerückt. ${ }^{85}$ Er ist zwar gleichfalls Teil einer Prosaerzählsammlung. Doch steht er in

81 Vgl. auch Stroszeck [Anm. 2], S. 90 ff.

8: Die serielle Anordnung einer Fazetienreihe und die über die Pointenstruktur bewirkte Abgeschlossenheit ihrer Einzelglieder hängen funktional zusammen: Die Proliferation der Kommunikation wird durch Terminierung der Texte bewirkt. Insofern ist die Formulierung "Das facete dictum reizt zum Weitererzählen (Barner, Überlegungen zur Funktionsgeschichte der Fazetien [Anm. 36], S. 291) zumindest missverständlich.

8:3 Zu den Markierungen dieser Serialität vgl. oben bei Anm. 49 u. 51.

84 Vgl. auch oben, Anm. 57.

45. Vgl. oben, S. 458. In der ,Gartengesellschaft< [Anm. 32] findet sich der größte Teil jener Schwänke, die auf Fazetien Bebels basieren, in zwei längeren Reihen (Nr. $25-74 ;$ Nr. 108-126), innerhalb derer die Prätexte zwar selektiv herangezogen werden, ihre ursprüngliche Abfolge in der Sammlung aber bis auf wenige Ausnahmen beibehalten ist. In der ersten der beiden Reihen übernimmt Frey von den sechs Fisilinus-Geschichten Bebels (I. 59-64) die Hälfte (I. 59, 60, 62 für Frey Nr. 32, 33, 34). Obwohl die Geschichten also auch hier unmittelbar aufeinander folgen, schreibt Frey sie je verschiedenen, auch je unterschiedlich charakterisierten Protagonisten zu und löst damit offenbar ganz bewusst den Zusammenhang auf, der ihnen durch die Identität des $>$ Helden< Fisilinus gegeben war: Während dieser Zusammenhang bei Bebel auch sprachlich dadurch unterstrichen wird, dass die gemeinsame Referenz auf den [s]acerdos quidam notissimus der ersten Fazetie durch die stereotype Uberschrift der folgenden Geschichten (De eodem) und das jeweils den ersten Satz einleitende Demonstrativpronomen (Idem [...]) signalisiert wird, führt Frey zunächst einen anonymen questionierer ein (Nr. $32 ;$ S. $47, Z$. 5), dann einen reisenden grobe $[n]$, tolle $[n]$ pfaff mit Namen Holch (Nr. 33; S. 48, Z. 4), schließlich einen abermals namenlosen ar- 
dieser ganz für sich. So gibt es hier kein Allgemeines, sei es des homo facetus-Typus, sei es der Konfessionspolemik, zu welchem sich der Einzeltext als Paradigma verhalten oder das er - spezieller - exemplarisieren könnte. Paradigmatizität und Exemplarisierung setzen entweder die Irrelevanz von Normhierarchien, Legitimationsansprüchen und Subsumptionsverhältnissen für jetzt und hier (Bebel) oder aber ihre Abstimmung für immer und überall (Kirchhof) voraus, und davon, so wollte ich zeigen, kann bei Freys Schwank keine Rede sein. Normen, Verpflichtungsverhältnisse, Regulierungszusammenhänge werden in ihm kontingent. Sie werden als relevant gesetzt und können doch zugleich nicht aufeinander abgestimmt werden. Was im Konflikt von Priester und Official gültig oder im Gegenteil nichtig sei, kann hier nicht mehr gesagt werden.

Aufs Ganze dieser Textinterpretationen aber lässt sich vielleicht dieses bemerken: Es mag generell lohnend sein, bei Fazetien und Schwänken die eingefahrenen Wege von Stoff- und Gattungsgeschichte zu verlassen und analytisch genau zu werden, denn in den Niederungen des >niederen $<$ Erzählens sind komplexe Spuren epistemischer Verunsicherungen zu entdecken. Was indes speziell die Repräsentationen religiöser Praxis in frühmodernen Schwankerzählungen anbelangt, wäre von Fall zu Fall zu urteilen. So sehr Reliquienpraxis im 16. Jahrhundert ins Zentrum konfessioneller Konflikte gerät, so wenig kann das schwankhafte Erzählen von ihr immer schon eindeutig auf die Seite frühmoderner Pluralisierungen geschlagen werden. Solches Erzählen kann vielmehr einerseits als Ort konfessionalistischer Verarbeitung und Eindämmung sozialer, religiöser, ideologischer Differenz genützt werden. Andererseits steht es aber fallweise auch dort als Raum literarischen Probehandelns zur Verfügung, wo es schwer oder unmöglich zu sein scheint, Konkurrenzen relevanter Propositionen, Orientierungskomplexe oder Geltungsfonds durch Negativierung und Asymmetrisierung zu entschärfen. Dann dürfte indes von Pluralisierungen, auch solchen des Religiösen, die Rede sein.

Einstweilen offen bliebe hierbei allerdings, ob es sich allein um Verarbeitungs-, oder auch um Produktionsformen des frühneuzeitlichen Umbaus der Welt handelt.

MÜNCHEN

Peter Strohschneider

men Dorfpfaffen (Nr. 34). Während bei Bebel außerdem die Erwähnung von Dornstetten (I. 59) und die Anspielung auf Eberhard im Barte (I. 6I) eine Lokalisierung im sautornahen، schwäbischen Raum suggeriert, akzentuiert Frey demgegenüber die Partikularität der Geschichten auch durch unterschiedliche Schauplätze: Worms und Oppenheim (Nr. 32), Straßburg (Nr. 33) und der Odenwald (Nr. 34). 